\title{
Redes da política externa institucional brasileira: Circulações diplomáticas e relacionamentos do Ministério das Relações Exteriores
}

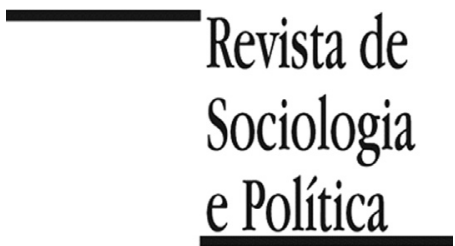

DOI $10.1590 / 1678-987320287504$

\author{
Rodolfo de Camargo Lima' (iD \\ 'Departamento de Sociología, Ciencia Política y Administración Pública, Universidad Católica de Temuco, Temuco, La \\ Araucanía, Chile.
}

PALAVRAS-CHAVE: Ministério das Relações Exteriores; análise de redes sociais; burocratas; políticas públicas; política externa.

RESUMO Introdução: Os padrões de participação e de circulação institucional dos diplomatas brasileiros permitem compreender a rede político-burocráticas do Ministério das Relações Exteriores e, logo, as prioridades de relacionamentos da política externa brasileira. Materiais e Métodos: A partir de informações das trajetórias dos diplomatas contidas no Anuário de 2010, analiso suas coparticipações em várias instituições de acordo com as posições funcionais que ocupavam na hierarquia ministerial. Para testar a hipótese de que as prioridades dos relacionamentos do Ministério se direcionam para embaixadas e consulados da classe " $\mathrm{A}$ ", para a Presidência da República e para a Organização das Nações Unidas, utilizo a metodologia de análise de redes sociais através das medidas de centralidade estrutural das conexões (eigenvector centrality) e de equivalência hierárquica de agrupamentos (hierarchical clustering). Resultados: A estrutura das redes mostrou uma alta concentração do tipo centro-periferia. De um lado, destacaram-se entre os postos diplomáticos classe "A", especialmente Buenos Aires e Washington. De outro lado, a Organização das Nações Unidas e a Presidência da República foram as instituições que apresentaram os mais elevados índices de centralidade e equivalência estrutural hierárquica dentre os estratos funcionais analisados. Discussão: Os postos diplomáticos da capital Argentina, para as camadas baixas e médias, e da capital dos Estados Unidos, para a elite ministerial, reforçam que as interdependências relacionais da política externa institucional brasileira permanecem próximas a dois principais e tradicionais parceiros estratégicos do Brasil. A Organização das Nações Unidas e a Presidência da República evidenciam o fato de que o domínio político do Itamaraty alcança, simultaneamente, os âmbitos externo e interno. Por sua natureza político-burocrática, o Ministério das Relações Exteriores tem de fomentar oportunidades e fluxos com essas instituições para manter, angariar e coordenar recursos, permitindo implementar redes de políticas públicas a nível doméstico, internacional e multilateral.

Recebido em 16 de Agosto de 2019. Aprovado em 30 de Junho de 2020. Aceito em 28 de Agosto de 2020.

\section{Introdução ${ }^{1}$}

\footnotetext{
${ }^{1}$ Agradeço os comentários de Eduardo Marques (DCP-USP), Renata Bichir (EACH-USP), Guilherme Casarões (FGV-EAESP), Felix Lopez (IPEA), Lucas Ribeiro Mesquita (UNILA), André Luiz Coelho Farias de Souza (UNIRIO), Lorena Granja (UERJ), Gisela Zaremberg (Flacso-México) e aos pareceristas anônimos da Revista de Sociologia e Política. O presente trabalho contou com o financiamento da Capes-Proex (Código 001), do DCP-USP (IPSA-USP Summer School), e em sua etapa de conclusão, teve apoio do Projeto de número 11200625 pertencente ao Fondo Nacional de Desarrollo Científico y Tecnológico,
}

$\mathrm{Q}$ uais são as redes político-burocráticas do Ministério das Relações Exteriores? O presente artigo mapeia as participações institucionais dos diplomatas com o objetivo de construir os relacionamentos do Ministério das Relações Exteriores (MRE ou Itamaraty), ou em outras palavras e como intitulo: as redes da política externa institucional brasileira. Projetar essas co-participações diplomáticas em redes permitem acessar a estrutura de onde se processam parcela significativa das políticas públicas do ministério - vulgo as policy networks do MRE. De outro lado, avanço no entendimento das relações entre burocratas, o ministério e seus sistemas políticos, analisando como se configuram as conexões e estruturas institucionais e relacionais prioritárias do Itamaraty.

A fonte do artigo tem como base o Anuário de Pessoal do MRE Diplomatas 2010, cujo banco de dados foi construído e sistematizado pelo autor. Para conectar as participações institucionais dos diplomatas utilizo o método de análise de redes sociais e dois de seus instrumentos: o eigenvector centrality (a centralidade baseada na força estrutural das conexões) e o hierarchical clustering (a medida de agrupamentos hierárquicos e estruturais das redes). Ao mirar para as participações institucionais dos diplomatas, externas a Secretaria de 
Fondecyt Iniciación, da Agencia Nacional de Investigación y Desarrollo (ANID) do Ministerio de Ciencia, Tecnología,

Conocimiento e Innovación (Gobierno de Chile), em que o autor é pesquisador principal.
Estado (SERE), as hipóteses da literatura sugerem que os relacionamentos prioritários do Itamaraty se direcionariam para a Presidência da República, a Organização das Nações Unidas (ONU), e consulados e embaixadas pertencentes a classe "A". Os resultados do artigo confirmam essas hipóteses e estreitam o escopo para os postos diplomáticos.

Nesse sentido, as redes do Itamaraty se caracterizam por um típico formato centro-periferia. Em relação aos resultados das medidas, os padrões de interdependência expõem a ONU e a Presidência da República como as instituições mais centrais e estruturalmente equivalentes do Ministério das Relações Exteriores. Em específico e para as embaixadas e consulados da classe "A", destacam-se mais sistematicamente os postos diplomáticos em Buenos Aires e Washington.

Além da presente introdução (I), o artigo divide-se entre uma seção teórica (II), outra metodológica (III), uma de resultados (IV), e a última de conclusão (V). Assim e para as duas próximas subseções teóricas, trato primeiramente da literatura de análise de política externa e a análise de redes sociais (ARS), e posteriormente, sobre pesquisas contemporâneas que aplicam ARS - principalmente de artigos nacionais com objetos de estudo burocráticos. A terceira seção contém os dados, o desenho de pesquisa e a metodologia. Por fim apresento os resultados e as discussões, e a última seção de conclusão sintetiza os principais achados do artigo.

\section{Seção teórica}

II.1 Análise de política externa e análise de redes sociais

A literatura recente em política externa brasileira tem apontado para uma maior pluralização de seus atores (Cason \& Power, 2009) ou para uma horizontalização e verticalização de seu processo decisório (Pinheiro \& Milani, 2012), sugerindo que esse domínio político pode ir além da centralização e monopólio do MRE. Outros estudos reiteraram a presença do legislativo em matérias de política exterior (Diniz \& Ribeiro, 2008) ou mesmo o crescimento de burocracias internacionais em diversos setores do poder executivo federal (França \& Badin, 2010).

Em paralelo a essas e outras importantes investigações, pesquisas pouco acessaram o papel dos próprios diplomatas tanto em determinados processos de política externa quanto em tais diversificações de arenas decisórias. Nesse aspecto e como proponho no presente artigo, as redes de relacionamentos do MRE podem sugerir uma via de compreensão empírico-relacional dos palcos dessas interações. Para tanto, o Anuário Diplomatas 2010 que detém todos os currículos de diplomatas pertencentes ao quadro ministerial nesse ano, permite desenhar as redes político-burocráticas do Itamaraty pela via das co-participações institucionais de seus atores, oferecendo uma proxy fundamental dos relacionamentos do MRE. Assim, tanto instituições mais centrais, estruturalmente equivalentes e preferenciais, quanto aquelas mais distantes e marginais, são resultados dos canais de policies advindos das co-participações institucionais construídas, desenvolvidas e consolidadas pelos atores ministeriais ao longo do tempo. Até o momento da atualização das informações desse banco de dados, em 2010, pode-se afirmar que o Itamaraty seguia com alta capacidade de coordenação, produção e implementação da política externa nacional, reforçando ainda mais a importância de conhecer suas policy networks.

Reitera-se, todavia, que essas redes permitem acessar a estrutura institucional dos relacionamentos do ministério, mas não o conteúdo político transferido, o recurso diplomático intercambiado, ou o aperto de mão que sela o 
acordo negociado pelos atores nas interações que estabeleceram em suas trajetórias. Em outras palavras, os achados aqui apresentados oferecem um output das conexões e da estrutura de relacionamentos da política externa institucional do MRE, porém não se alcança o outcome dessas redes de policies. Isso significa que o enfoque sugerido pelo artigo confere peso ao quadro relacional e estrutural construído pelas relações do Itamaraty, sem extrapolar o impacto ou resultado que vem a reboque das atuações dos diplomatas nessas instituições. Esse elemento, contudo, tem também suas vantagens por lançar luz ao nível mais estrutural das foreign policy networks, ou seja, é capaz de capturar múltiplas dinâmicas, burocráticas e políticas, desse meio de campo relacional entre indivíduos, o ministério, e as instituições do sistema político doméstico e internacional.

Frente a essas complexas dinâmicas, as ferramentas de análise em política externa (APE) podem auxiliar a presente investigação com base em sua tradicional perspectiva político-burocrática (Allison, 1969). No chamado "modelo burocrático ou governamental", o papel burocrático, a posição dos atores (políticos e burocratas) e a missão organizacional, tem peso para o cálculo decisório do policymaking (idem). Nessa chave, os indivíduos por possuírem mandatos de suas instituições com distintos objetivos pessoais e organizacionais, terminam por configurar disputas por interesses e preferencias setoriais, de acordo com os objetivos de cada ator e a organização que representa (ibidem). As particularidades desse modelo levantaram limitações e críticas (Art, 1973; Krasner, 1972; Perlmutter, 2011; Rosati, 1981), entretanto equivalentemente reforçaram a relevância da competição "político-burocrática" (bureaucratic politics). Essa perspectiva analítica, desde então, passou a fornecer um importante instrumental para examinar a caixa-preta da tomada de decisão em política externa, com casos ilustrativos de sua capacidade explicativa (Jones, 2010; Marsh, 2013).

Adiciona-se a isso o fato de que a arena decisória não é exclusivamente resultado de disputas, mas também de múltiplos processos de interação entre os atores junto dos mecanismos institucionais, que são componentes fundamentais para explicar como preferencias individuais resultam em decisões coletivas e em policies (Stein, 2006). Os níveis do ator e suas relações institucionais portanto, estão presentes quando analisamos as redes institucionais da política externa, ainda que o artigo busque o campo relacional intermediário dos padrões estruturais construídos entre os agentes do ministério e as instituições. Isto é, uma das vantagens da utilização da APE e da abordagem aqui sugerida é seu caráter interdisciplinar com outras áreas do conhecimento, especificamente no diálogo entre a ciência política e políticas públicas (Hudson, 2013) junto do ferramental oferecido pela análise de redes (Hafner-Burton, Kahler \& Montgomery, 2009).

Em pontos de contato comum entre essas áreas, reforçamos que o principal pilar da política, o poder, é essencialmente relacional e os recursos que o alimentam não são construtores unitários, mas sim dependentes de uma ampla gama de conexões entre atores e recursos (McClurg \& Lazer, 2014). A política, então, envolve vários processos interdependentes desde a disputa até a delegação e o compromisso, decorrentes da interação dos atores de maneira não atomizada (Huckfeldt, 2009), em que um ou mais de um ator busca poder e vantagens a despeito da resistência dos demais (Wu \& Knoke, 2013).

Isso vale igualmente para o processo de produção de políticas públicas ou policymaking em que atores para obter recursos que não possuem, tem de estabelecer estratégias de sua obtenção com os demais atores, geralmente cedendo parte de seus próprios recursos para tal (idem). Desse modo, a policy network é concebida como uma estrutura de arranjo específica para o policy- 
making em que operam as organizações formais, tal qual um ministério - ou partidos, associações, grupos de interesse etc. (Kenis \& Schneider, 1991).

Analogamente, um domínio de política pública (policy domain) se constitui em um conjunto de atores com preocupações específicas em uma área substantiva, cujas preferencias e ações desses eventos políticos devem ser considerados por outros participantes de outros domínios de policies (Laumann \& Knoke, 1987). Os participantes ativos de um policy domain, por sua vez, incluem todas as organizações consequenciais que tem responsabilidade por direcionar, coordenar, ou mesmo controlar a criação e distribuição de domínios de valor que pertencem ao subsistema, ou que se relacionem as externalidades as quais estão inseridos (idem).

A proposta de pesquisar um ministério específico implica compreender que o policy domain desenha as fronteiras de seu subsistema em que seus componentes e parceiros organizacionais estão interconectados por uma ou mais policy networks (Wu \& Knoke, 2013). A análise de redes sociais (ARS) é apropriada para capturar essas interações político-burocráticas, de um e outro nível, pois ela lida com essa dualidade entre indivíduos e instituições (Breiger \& Mohr 2004). Diferente de uma estratégia metodológica de contagem de passagens para descrever trajetórias institucionais (Lima, 2019), a ARS permite analisar como as conexões inter-institucionais se configuram, equivalente e estruturalmente, nas redes do ministério. Assim, ao costurar as dinâmicas do meso-level (Wu \& Knoke, 2013), as redes revelam onde e qual a força dessas relações inter-organizacionais e inter-dependentes são mais relevantes para o policy domain institucional do Itamaraty.

Teoricamente a ARS tem entre seus fundamentos que (i) os atores e seus comportamentos são mutuamente dependentes, (ii) as conexões entre os atores são canais de transmissões materiais e não-materiais, e (iii) a persistência dos padrões entre os atores criam estruturas que definem, possibilitam ou restringem os comportamentos dos próprios atores (Hafner-Burton, Kahler, \& Montgomery 2009). Nesse quadro e de um lado, está a institucionalidade ministerial, o jogo político de captação e o intercâmbio de recursos da burocracia, que se relaciona as capacidades, autonomias e interdependências que o ministério possui frente aos sistemas políticos nacionais e internacionais. De outro e nesse compasso, há o acumulado das trajetórias institucionais dos burocratas do ministério, cujas motivações, objetivos, interesses pessoais e político-burocráticos, também interagem com os incentivos e constrangimentos advindos do ministério.

Nesse sentido, as co-participações institucionais de diplomatas podem, em última instancia, revelar maiores ou menores centralidades e hierarquias estruturais dos relacionamentos do MRE, tendo em vista que o ministério otimiza suas conexões preferenciais no processo das interações de seus atores. E o sentido inverso é igualmente válido, ou seja, os diplomatas também possuem relativa discricionariedade frente as suas carreiras, ainda que essa autonomia ora seja incentivada, ora limitada ou constrangida politicamente pelas demandas do MRE. A força da ARS reside exatamente nessa relação agente-estrutura e sua técnica relacional tem como objetivo construir padrões para essa via de mão dupla, em que os atores moldam a instituição e são também moldados por ela. Pressupõe-se, então, que as instituições com posicionamentos centrais e estruturalmente hierárquicos nas redes possibilitem participações e influências mútuas mais intensas nesses inter-eventos institucionais de policies (Laumann, Knoke \& Kim, 1987) - seja qual for os recursos que aí transitam do ponto de vista material ou não-material: informacionais, financeiros, culturais, simbólicos etc. 
Em outras palavras, as relações e as posições nas redes constituem estruturas relacionais que constrangem escolhas, dão acesso diferenciado a bens e instrumentos de poder, tornam certas alianças ou conflitos mais ou menos prováveis, influenciam os resultados da política e impactam de maneira importante as dinâmicas de poder no interior do Estado (Marques, 2006), e também entre Estados. Isto é, a movimentação de pessoas entre instituições gera consequências relevantes para a coordenação de políticas, a disseminação de informações e a estabilidade na produção de políticas (Marques, 2017).

\section{2 Burocratas e burocracias em redes}

Na ciência política, a análise de relacionamento entre agentes políticos (indivíduos, instituições ou Estados) por meio da utilização de análise de redes sociais (ARS) tem aumentado na literatura internacional (Ward, Stovel \& Sacks 2011; McClurg \& Lazer, 2014). Sua utilização e reconhecimento como um ferramental importante ou complementar na explicação das relações internacionais também tem sido reforçado por autores da área (Hafner-Burton, Kahler \& Montgomery, 2009).

As teorias de ARS, em específico, possuem três pressupostos típicos sobre a mútua influência dos atores: (i) que a estrutura social de qualquer sistema complexo consiste em padrões estáveis de repetidas interações conectando um ator ao outro; (ii) que essas relações sociais são a unidade de análise primária e exploratória, ao invés dos atributos e características individuais dos atores; e (iii) que as percepções, atitudes e ações dos atores são moldadas pelas estruturas múltiplas de rede aos quais estão inseridos, e em troca, seus comportamentos podem mudar as estruturas da rede (Knoke, 2001). As political networks se constituem portanto, em um subset das redes sociais, em que as relações entre os atores envolvem inequidades de poder, sendo que essas assimetrias de poder político nas instituições, raramente dependem da força coercitiva pura e simples, mas geralmente se fundam no poder legítimo de possessão da autoridade de comando, além da expectativa de compliance mediante o endereçamento de ordens aos demais atores (Wu \& Knoke, 2013).

Nessa chave toda policy network possui dois pressupostos estruturadores de sua lógica. Um primeiro é de que os atores são racionais e estão dispostos a intercambiar recursos - se assim se beneficiarem -, e o outro é que todo intercambio em policy envolve desiquilíbrios de poder, e toda mudança de policy também resulta em algum desiquilíbrio (idem, p. 158). Nesse aspecto, reforça-se que há ganhos na utilização da ARS, ao se permitir integrar os atores em seus contextos relacionais específicos sem necessariamente abandonar os pressupostos ligados à sua racionalidade (Marques, 2006, p. 200). Ainda que essa rationale ganhe contornos distintos na literatura de ARS quando comparada a sua praxe na ciência política e na economia (idem), tal abordagem se aproxima teoricamente da vertente neo-institucionalista, especialmente para os estudos que enfatizam poder e influência de grupos em ambientes organizacionais (Lopes \& Baldi, 2009).

A produção acadêmica brasileira igualmente tem se utilizado da análise de redes em pesquisas sobre burocracias. Cepik e Möller (2017) por exemplo, compararam as organizações de inteligência dos países dos BRICS, utilizando medidas de centralidade. Os resultados apresentados por esses autores mostram que os presidentes russo e brasileiro possuem maior autoridade sobre os sistemas de inteligência; que a ABIN possui alto controle de fluxo de informação; a Rússia apresenta maior vulnerabilidade e resiliência ao risco organizacional; e por fim, a China se mostra como o país com o maior risco de unilateralmente reter informações. 
Já Olivieri (2007) explorou os padrões de indicação, técnicas e políticas, nas nomeações dos diretores do Banco Central (BC) e concluiu que os diretores de política econômica são recrutados majoritariamente fora do Banco, enquanto os diretores de fiscalização advêm, em sua maioria, do corpo burocrático do próprio BC. Diante desse mesmo objeto, Perissinotto et al. (2017) mapearam as carreiras dos diretores e presidentes do $\mathrm{BC}$ e revelaram que a maioria se constrói de maneira mista entre o setor público e o privado; esses atores possuem formações econômicas universitárias concentradas (USP, FGV-RJ e PUC-Rio); além de ressaltarem suas conexões com o mercado, principalmente o setor financeiro.

Por meio de entrevistas em cascata, Baird (2020) analisou a circulação público-privada nas diretorias da Agência Nacional de Saúde Suplementar (ANS) e constatou não apenas como setores do empresariado de saúde assumem determinadas diretorias na ANS, como miram controlar sistematicamente a Diope - diretoria responsável pela regulação desse mercado. Já em pesquisa voltada para a burocracia ao nível de rua, Lotta (2018) ao entrevistar agentes comunitários de saúde que atuam em diferentes unidades básicas, constatou que suas redes ainda que concentradas onde residem, se expandem conforme o tempo de carreira dos agentes, além de impactar e se relacionar a entrega de serviço público e a efetivação de direitos.

Já Marques (2017) pesquisou a migração de ocupantes de cargos de alto escalão do poder executivo municipal de São Paulo e verificou que as redes de burocratas se associam a ideologias, setores de políticas, escalas e técnicas de especialização distintas, ao longo dos governos. $\mathrm{O}$ autor identificou que a rede conecta entre si governos com afinidades político-partidárias principalmente do campo da direita e, em termos setoriais, observou que as agências de gestão e articulação política são as mais centrais, enquanto as burocracias da área social estão na periferia da rede.

Em relação a literatura internacional, o trabalho seminal de Laumann \& Knoke (1987) mostrou que são as organizações e não indivíduos, os principais atores nas decisões de política pública de energia e saúde. O livro revela a existência de redes inter-organizacionais similares de influência nesses domínios, com um alto número de atores privados e instituições públicas, sendo que os atores dessas últimas instancias ocupavam posições mais centrais em ambas as redes. Um estudo posterior comparando EUA, Alemanha e Japão constatou resultados similares (Knoke et al., 1996).

\section{Dados, desenho de pesquisa e o MRE}

As construções das redes do presente artigo foram feitas com base em um banco original elaborado pelo autor que tem como fonte o Anuário de Pessoal do MRE Diplomatas 2010. Nele constam os currículos de todos os diplomatas ativos $(n=1466)$ e aposentados $(n=18)$ nesse ano no ministério e toda a base foi considerada - o banco possui todas as informações a respeito das trajetórias dos diplomatas, desde o momento de aprovação no concurso até 2010. Para a construção e configuração da base utilizei o Excel, para a conversão matricial e análise de trajetória foi utilizado o programa Ucinet (Borgatti, Freeman \& Everett, 2002), para as demais medidas usei o software Pajek (Batagelj \& Mrvar, 1996), e para o desenho das redes esse último foi pareado e projetado com o VOSviewer (Eck \& Waltman, 2009).

Divido as redes de acordo com a hierarquia diplomática do indivíduo, ou seja, agrupo os atores conforme sua posição funcional máxima ocupada no ministério com base nos últimos registros do Anuário. Essa divisão parte do pressuposto de que as diferentes hierarquias da carreira diplomática possuem 
2 As regras de promoção estão disponíveis no site do Sindicato de Servidores do Itamaraty (Sinditamaraty). dinâmicas particulares que vão desde o tempo de trajetória, autoridade, autonomia, discricionariedade político-burocrática em sua atuação institucional, até particularidades e idiossincrasias que o ministério possui sobre os mandatos de policies que endereça aos agentes de seus estratos funcionais. Assim e se tomamos como referência a perspectiva top-down (Foss, 1995), burocratas ao topo da instituição são tidos como tomadores de decisão (Ostrom \& Ostrom, 1971) ou policymakers (Aberbach, Putnam \& Rockman 1981; Huber, 2007), enquanto os do médio escalão as acompanham, e os do baixo escalão são responsáveis por implementá-las, ou supervisionam sua implementação $(\mathrm{Hu}-$ ber, 2007).

Nessa cadeia de comando, os que estão ao topo dão mais ordens do que as recebem, os do meio escalão dão e recebem ordens, e os do baixo escalão recebem ordens exclusivamente (idem), e esse desenho e funcionamento institucional adequa-se ao MRE que obedece a uma carreira profissional em escada e lógica hierárquica ministerial restritiva. Isto é, uma vez que o indivíduo é aprovado no Concurso de Admissão a Carreira Diplomática ingressa automaticamente no escalão inicial de terceiro secretário, podendo então proceder a segundo e primeiro secretário, depois conselheiro, e finalmente alcançar a elite diplomática, composta pelas posições de segundos e primeiros ministros (vulgo embaixador). As promoções ocorrem semestralmente por meio de um complexo sistema de avaliação vertical e horizontal, coordenada e deliberada por atores da elite do ministério. Nesse processo, predominam o critério de merecimento a partir da segunda ascensão funcional, ao que se incluem requisitos mínimos de tempo em postos no exterior e/ou cargos de confiança no executivo federal, além da exigência de cursos no IRBr, que permitem a progressão funcional de seus atores ${ }^{2}$. A institucionalidade do ministério está presente nesse processo e sistematicamente influencia as carreiras de seus burocratas, ao passo que outros processos político-burocráticos, por parte da atuação particular de cada um dos diplomatas, também desempenham dinâmicas individuais e coletivas que resultam no desenvolvimento e funcionamento ministerial.

Do ponto de vista histórico, a institucionalização do MRE é relatada como um extenso e particular processo de profissionalização e racionalização weberiana (Cheibub, 1985) que fora impactado e influenciou o serviço público nacional (Abrucio, Loureiro \& Pacheco, 2010) - tida em parcela significativa dessa consolidação como insulada de demandas particularistas e partidárias (Geddes, 1996). Nesse aspecto, inclui-se contemporaneamente, um baixo percentual de indicações a cargos de confiança para atores de fora da carreira (Lopez, 2015), constituindo-o no ministério civil mais fechado da burocracia federal (Loureiro \& Abrucio, 1999), elemento que se associa a uma alta autonomia e capacidades burocráticas (Bersch, Praça \& Taylor, 2017). Essas características típicas do MRE (Cheibub, 1985; 1989) corroboraram para as manutenções dos perfis sociais de seus atores, com poucas alterações nos padrões de promoção à elite diplomática (Lima \& Oliveira, 2018).

Essa inércia e resiliência, resultado de sua institucionalização paulatina, histórica e burocraticamente fechada, se constituem em vantagens enquanto objeto de pesquisa, pois a baixa variação da composição do ministério no tempo, conjuntamente as lentas dinâmicas de alterações na carreira e das linhas gerais de política externa, até então, permitem construir um retrato mais fiel dos padrões dos relacionamentos institucionais dessa burocracia. Isso porque não apenas indivíduos em posições de autoridade tem importância na tomada de decisão (Hudson, 2013), como os processos organizacionais igualmente desempenham papel explicativo significativo na análise de política externa (Allison, 1969; Jones, 2010; Marsh, 2013). 
3 Apenas 3 terceiros-secretários tiveram mais de uma passagem - sendo que 56 tiveram uma passagem -, de um total de 264 registrados na base Diplomatas 2010.
${ }^{4}$ Conforme o Regimento Interno da Secretaria de Estado das Relações Exteriores. Para mais acessar:
Cabem duas considerações a respeito dos padrões de relacionamentos institucionais dos atores proposto pelo artigo. Uma já supracitada, se refere a construção das redes conforme as hierarquias funcionais pertencentes a pirâmide ministerial - composta pelos secretariados, conselheiros, segundos ministros e embaixadores. A outra seria a respeito das trajetórias individuais que variam em um continuиm da participação institucional do ator (Laumann, Knoke \& Kim, 1987). Nesse sentido e em um polo, os eventos políticos ou as participações por instituições podem ser entendidos como independentes um do outro, ou seja, a participação de atores em uma instituição pode ser relativamente aleatória em relação a participação deles em uma segunda, e assim sucessivamente. No outro polo, esses eventos políticos podem ser completamente dependentes um do outro, tanto no sentido causal em que o evento imediatamente anterior é condição necessária e suficiente para o evento subsequente, quanto no sentido estratégico de que a preferência de um ator para a participação em um segundo evento pode ser constrangido pelo comportamento relacionado ao primeiro (idem, p. 289). Ainda que esses elementos sejam essenciais, a preocupação fundamental do artigo não é com a interdependência temporal, tampouco com a modelagem em cadeia desses eventos políticos, mas sim e em que medida a participação dos atores em determinadas instituições determina a estrutura das co-ocorrências desses relacionamentos, configurando-os em redes.

Desse modo a base de dados tem as co-participações institucionais dos diplomatas, em díades, desenhando os relacionamentos posicionais e estruturais mais amplos ao examinar todas as díades possíveis - mirando, portanto, mais ou menos um ponto médio do continuum teórico de participação (ibidem). Como supra pontuado, há uma elevada complexidade nessa dinâmica que envolve desde a discricionariedade individual do diplomata e sua atuação institucional, até as capacidades e mandatos burocráticos do ministério - tanto no sentido de controlar, incentivar ou constranger seus atores, quanto sua interface exógena, que envolvem sua autonomia ministerial relativa frente aos recursos, necessidades e demandas para com os sistemas políticos domésticos e internacionais que interage.

Com a finalidade de capturar os padrões de interações políticos-burocráticos que ocorrem nesse meio campo relacional, utilizamos como objeto de análise apenas os diplomatas que passaram, no mínimo, por duas instituições externas a Secretaria de Estado (SERE), no decorrer dos seus registros de carreira. Consequentemente os terceiros secretários $(\mathrm{n}=264)$ foram desconsiderados pelo artigo, tendo em vista que a quase totalidade desse grupo não possui mais de uma passagem por instituições, exógenas a SERE, desde seu ingresso no concurso ${ }^{3}$ pois os primeiros anos na carreira são sobretudo dedicados a formação académico-diplomática no Instituto Rio Branco. Para os segundos secretários $(\mathrm{n}=226), 86$ passaram por no mínimo duas instituições, para os primeiros secretários $(\mathrm{n}=256)$ temos 215 atores com pelo menos dois registros, entre os conselheiros $(n=302)$ se alcançaram 300 diplomatas com esse critério, para os segundos ministros $(\mathrm{n}=240)$ foram 226 indivíduos que obedeceram esses quesitos e, para o topo da carreira $(n=196)$, se chegou em 185 embaixadores com duas ou mais passagens por instituições. Por conseguinte, frente a um subtotal de 1220 indivíduos (descontados os terceiros secretários) e sob os critérios propostos, a amostra analisada resultou em 1012 atores, equivalente a 82,95\% desse subset ou 68,19\% do total do banco.

Faz-se também fundamental ressaltar que a estrutura burocrática do MRE é dividida basicamente entre a Secretaria de Estado (SERE) e suas repartições no exterior ${ }^{4}$. Como o objetivo da investigação é observar o relacionamento institucional do ministério, se desconsidera seu trânsito junto a SERE. Reitera-se que essa é a base que o diplomata frequentemente retorna, uma vez que é removido ao exterior ou mesmo transferido ou emprestado para outra instituição. Dessa 
http://www.itamaraty.gov.br/i mages/RISE.pdf maneira, a pesquisa leva em consideração os relacionamentos institucionais exógenos a SERE, ou seja, uma vez que o diplomata se desloca seja para repartições do MRE no exterior - como consulados e embaixadas ou demais unidades específicas -, seja para outras instituições políticas nacionais - em outros ministérios, prefeituras, congresso, Presidência etc. -, ou para organismos internacionais - via missões diplomáticas ou demais serviços -, a pesquisa se utiliza dessas díades para construir as co-participações institucionais dos burocratas em redes, analisados de acordo com sua hierarquia funcional.

Cabe salientar que as repartições no exterior são classificadas oficialmente pelo ministério da seguinte forma: (i) missões diplomáticas permanentes - que envolvem embaixadas, delegações permanentes e missões junto a organismos internacionais -, (ii) consulados, e (iii) unidades específicas - destinadas a atividades administrativas, técnicas, culturais ou de gestão de recursos financeiros. Em relação as missões junto a organismos internacionais e demais serviços prestados a organismos internacionais - sejam formais ou informais -, estes estão classificados nas redes de acordo com a sigla do organismo tal como consta no Anuário.

As instituições nacionais foram agrupadas em nove categorias, referentes as circulações dos diplomatas registradas em âmbito doméstico, sendo que: (i) "Ministérios" compõe os serviços, assessorias e cargos ocupados em algum outro ministério, exceto o próprio MRE, ou às burocracias não autárquicas incluídas ou pertencentes ao guarda-chuva institucional desses mesmos ministérios; (ii) "Legislativo Federal" agrega assessoria ou serviços prestados a burocracia da Câmara e/ou do Senado Federal, ou a assessoramentos a políticos pertencentes a alguma dessas casas; (iii) "Executivo Estadual" envolve igualmente prestação de serviços aos governos, políticos profissionais, secretarias e/ou burocracias do âmbito estadual; (iv) "Executivo Municipal” igual ao ponto anterior mas relacionado ao poder executivo municipal; (v) "Exército" abrange assessorias e demais apoios às instituições maiores do exército e escolas superiores militares; (vi) "Agencia" agrupa serviços oferecidos às agências autárquicas nacionais; (vii) "Judiciário Federal" se relaciona as assessorias e prestação de serviços aos Supremo Tribunal Federal (STF) e de Justiça (STJ), além do Tribunal Superior Eleitoral (TSE); a (viii) "AGU” (Advocacia Geral da União) que por ser uma instituição de função essencial à justiça, foi reservada uma categoria exclusiva; e, (ix) por último porém não menos importante, a "Presidência da República" que abarca os serviços prestados seja ao presidente ou ao vice-presidente, seja a algum setor da própria burocracia presidencial em si.

É importante reiterar que as embaixadas, consulados e unidades específicas no exterior são referidas nas redes de acordo com o nome das cidades onde que estão situados esses postos diplomáticos - sem especificar sua natureza, isto é, se é consulado, embaixada ou unidade específica. Para os organismos internacionais também não se específica na rede se é uma missão diplomática, assessoria a alguma burocracia da organização ou prestação de apoio a determinada iniciativa, mencionando apenas o nome do organismo. De maneira similar, para as instituições nacionais, igualmente não se especifica a natureza do serviço prestado, se o diplomata foi emprestado ou transferido temporariamente, referindo-se apenas as categorias supracitadas.

Note, nesse aspecto, que a natureza dos dados do banco se constitui como de tipo "afiliações" (pessoa-por-evento), em que se tem o indivíduo e suas participações em determinadas instituições ao longo da trajetória profissional registrada - com os indivíduos na primeira coluna e as instituições nas demais. Construiu-se, dessa maneira, uma matriz diplomata-por-instituições de tipo bipartite, cujas relações ocorrem entre as entidades - mas nunca internamente a 
5 Uma matriz one-mode projeta todos os nós, ligados uns aos outros, sob a forma de cliques - todo ator é adjacente a todo ator desse subgrupo, de modo que se faz impossível adicionar mais atores ao clique essas entidades -, ou seja, o banco está formatado a princípio como uma matriz bimodal (two-mode) - referente as diferentes entidades nas linhas e colunas da matriz (Borgatti \& Halgin, 2011). Faremos adiante uma transformação nessa matriz, todavia e antes de efetuá-la, observe os tempos de carreira de acordo com a hierarquia funcional, respectivamente acompanhados pela quantidade média de instituições que os indivíduos transitaram (Tabela 1).

Desse modo, observe que na base ministerial se tem pouco mais de duas instituições transitadas, em média, ao longo de quase seis anos de carreira, especificamente para os segundos secretários analisados. Já no nível mais alto da burocracia, se tem em média, pouco mais de sete instituições percorridas para uma trajetória de quase 38 anos de carreira dos embaixadores.

Adiciona-se que não há controle temporal sobre o ano de entrada ou saída das múltiplas instituições transitadas. As redes desenhadas a seguir têm como base as co-participações institucionais dos indivíduos - ao longo do tempo e conforme cada uma de suas hierarquias funcionais -, ou seja, o ponto de partida são as co-ocorrências dessas passagens dado que o objeto de investigação se direciona exclusivamente para a estrutura de relacionamento institucional do ministério.

Tendo em vista esse objetivo e para fins de análise dos relacionamentos institucionais, a matriz de afiliação bimodal foi transformada para unimodal (one-mode). A partir dessa conversão, a matriz retangular e assimétrica diplomata-por-instituição anterior, se torna uma matriz quadrada e simétrica instituição-por-instituição, fornecendo um par de instituições que no mínimo um diplomata co-participou - o que possibilita a contagem das co-participações institucionais pelos atores do ministério. Essa transformação, portanto, conecta um dos tipos de nós com base na soma dos produtos cruzados (para a coluna instituições $)^{5}$, tal qual uma tabela de contingência. Assim temos as co-ocorrências de participações de diplomatas por instituições (overlaps), em um quadrante, mediante as co-ausências (co-absent) nos demais. Em outras palavras, a matriz unimodal resulta em uma estrutura em que as instituições centrais possuem maiores co-participações institucionais e nos seus arredores constam as outras instituições com menores co-ocorrências, chegando até as instituições

Tabela 1 - Estatísticas descritivas do tempo de carreira (em anos, acima) e análise da trajetória das participações dos diplomatas por instituições (rede bimodal, abaixo)

\begin{tabular}{|c|c|c|c|c|c|c|}
\hline \multicolumn{2}{|c|}{ Descritivo das hierarquias } & \multirow{2}{*}{$\begin{array}{c}\begin{array}{c}\text { Segundo } \\
\text { Secretário }\end{array} \\
5.790\end{array}$} & \multirow{2}{*}{$\begin{array}{c}\begin{array}{c}\text { Primeiro } \\
\text { Secretário }\end{array} \\
11.362\end{array}$} & \multirow{2}{*}{$\begin{array}{c}\text { Conselheiro } \\
23.89\end{array}$} & \multirow{2}{*}{$\begin{array}{c}\begin{array}{c}\text { Segundo } \\
\text { Ministro }\end{array} \\
29.995\end{array}$} & \multirow{2}{*}{$\begin{array}{c}\text { Embaixador } \\
37.945\end{array}$} \\
\hline $\begin{array}{l}\text { Tempo de } \\
\text { carreira }\end{array}$ & $\begin{array}{l}\text { Média do tempo } \\
\text { (anos) }\end{array}$ & & & & & \\
\hline (Estatística & Desvio padrão & 3.713 & 4.623 & 8.309 & 6.674 & 5.694 \\
\hline & Mínimo & 3 & 4 & 10 & 17 & 24 \\
\hline & Máximo & 26 & 27 & 49 & 47 & 49 \\
\hline & N (indivíduos) & 86 & 215 & 300 & 226 & 185 \\
\hline \multirow{4}{*}{$\begin{array}{l}\text { Análise de } \\
\text { trajetória } \\
\text { (Node-Level } \\
\text { Trajectory } \\
\text { Measures) }\end{array}$} & $\begin{array}{l}\text { Média de institui- } \\
\text { ções transitadas }\end{array}$ & 2.174 & 2.716 & 5.557 & 6.655 & 7.703 \\
\hline & Desvio padrão & 0.685 & 1.173 & 2.750 & 2.445 & 2.250 \\
\hline & $\begin{array}{l}\text { Máximo de insti- } \\
\text { tuições transitadas }\end{array}$ & 4 & 9 & 16 & 16 & 15 \\
\hline & $\mathrm{N}$ (indivíduos) & 86 & 215 & 300 & 226 & 185 \\
\hline
\end{tabular}

Fonte: Elaborado pelo autor com base no Anuário de Diplomatas 2010. Utilizado Ucinet > Network > Trajectories. 
sem violar essa condição. Assim a projeção é, em geral, a união de um número de cliques, um para cada grupo, da matriz original bipartite (Newman, 2010, p. 124-6) menos frequentes e consequentemente mais periféricas na rede - ou mais co-ausentes na circulação diplomática brasileira.

Reitera-se que as co-participações não são normalizadas e a matriz constitui-se como valorada ou valued data, pois assumiremos "co-affiliation as opportunity" (Borgatti \& Halgin, 2011), o que significa que as co-ocorrências de passagens por instituições podem ser interpretadas como oportunidades de interação, fluxo de informações, recursos, bens, serviços e policies (idem), logo, próprios da rede de relacionamentos políticos e institucionais do MRE. Em síntese e de maneira simplificada, as redes cruas ilustram a frequência desses eventos inter-conectados, vulgo as co-participações institucionais dos atores do ministério.

Para verificarmos a macroestrutura das redes, a medida mais simples intitulada de grau (degree), também chamada de grau de centralidade (centrality degree), é utilizada na literatura de ARS para mensurar o número de conexões que um nó ou ator possui ${ }^{6}$ (no caso: instituições). Nós com altos graus tendem a possuir mais conexões, maior acesso à informação ou prestígio, logo são mais influentes do que aqueles menos conectados na rede (Newman, 2010) - lógica que igualmente se aplica as organizações (Borgatti, Everett \& Johnson, 2013). Isso porque se assumirmos que existem fluxos por esses nós, essa medida se constitui em um índice de exposição, e se andarmos aleatoriamente pela rede a probabilidade de chegarmos em um nó particular é proporcional ao seu grau (idem). Note, abaixo, que ao aplicarmos a partição para a medida de grau, não somente as redes evidenciam suas configurações em um formato centro-periferia, como a complexidade das matrizes das instituições co-participadas aumenta, ao compararmos os níveis hierárquicos baixos e médios do Gráfico 1 com a alta elite ministerial de segundos ministros e embaixadores no Gráfico 2.

Observe que a medida de grau se associa a conectividade da rede que, por sua vez, corresponde a chamada coesão da rede. A medida mais simples para se medir a coesão é a densidade, contudo como a densidade varia de acordo com o tamanho dos grupos, a média do grau se mostra mais intuitiva e simples para vias de comparação (ibidem) e é mensurada por meio da média do número de conexões que cada nó possui ${ }^{7}$. Na Tabela 2 os secretariados apresentam as menores médias, enquanto os conselheiros e segundos ministros apresentam as maiores médias de grau, inclusive com conexões acima dos valores médios dos embaixadores - que, todavia, é o grupo funcional que possui as maiores máximas de degree, quantidade de instituições transitadas e de desvio-padrão.

\footnotetext{
7 Considerando que a média de grau $c$ de um ator em uma rede indireta é $c=\frac{1}{n} \sum_{j=1}^{n} k_{i}$,

basta combinarmos essa formula a soma de todos os
}

\footnotetext{
atores e denotando o grau do ator $i$ como $k_{i}$, temos em uma Considerando que a rede institucionais possuem duas há $m$ laços no total então graus de todos os atores,
}

Gráfico 1 - Matrizes com partição para grau de centralidade da base e escalão intermediário

Segundo Secretário

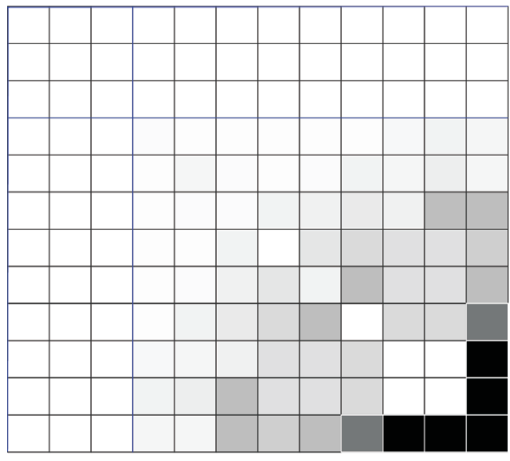

Primeiro Secretário

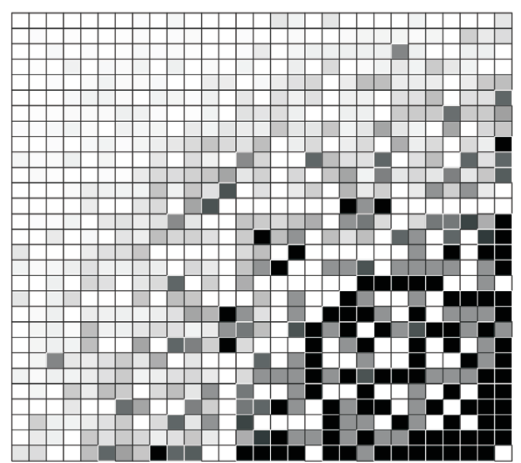

Conselheiro

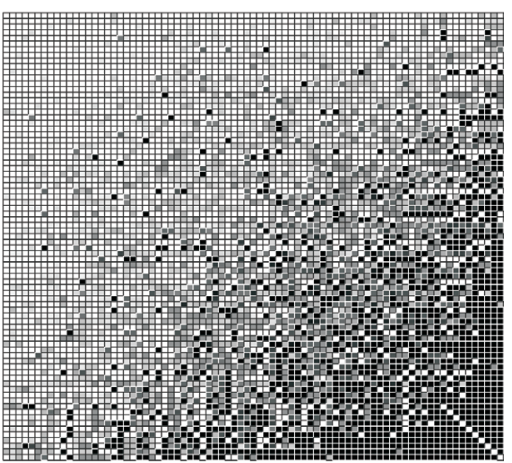

Fonte: Anuário Diplomatas 2010, elaboração do autor. Utilizado Pajek > Network > Export as Matrix > Using Partition (degree all) $>$ Structural. 
graus da rede que temos: $c=\frac{2 m}{n}$.
Gráfico 2 - Matrizes com partição para grau de centralidade da elite ministerial
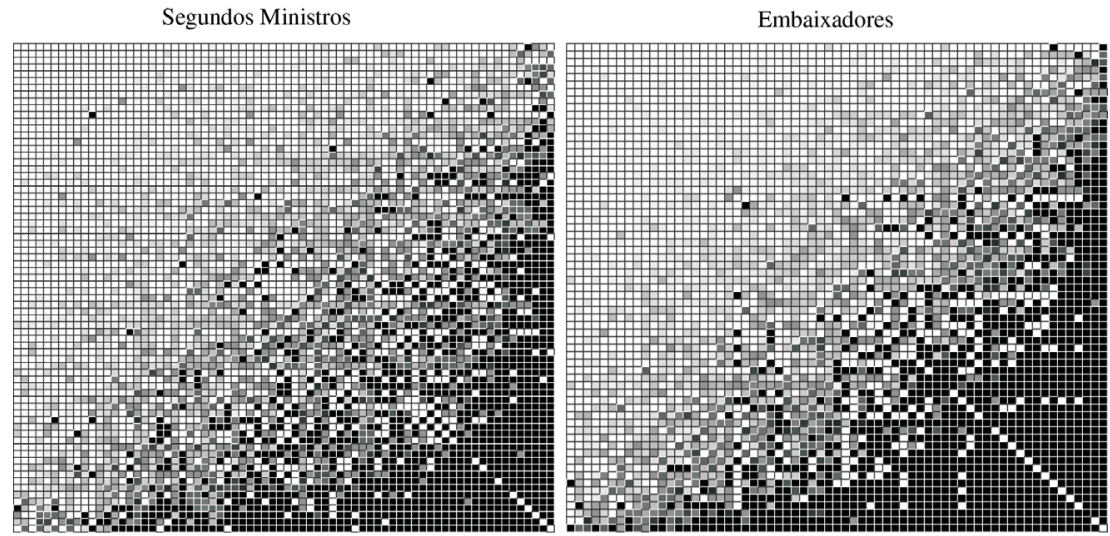

Fonte: Anuário Diplomatas 2010, elaboração do autor. Utilizado Pajek > Network > Export as Matrix $>$ Using Partition (degree all) $>$ Structural.

Tabela 2 - Média e mediana do grau das redes por hierarquia funcional

\begin{tabular}{lccccc}
\hline & Segundo Sec. & Primeiro Sec. & Conselheiro & Segundo Ministro & Embaixador \\
\hline Média & 5.741 & 17.240 & 76.694 & 68.062 & 59.886 \\
Mediana & 4.000 & 14.000 & 74.000 & 56.000 & 42.000 \\
Mínima & 0 & 2 & 6 & 8 & 8 \\
Máxima & 30 & 74 & 226 & 266 & 324 \\
Desvio-padrão & 5.511 & 14.531 & 48.643 & 51.303 & 54.592 \\
N (instituições) & 85 & 129 & 190 & 191 & 211 \\
\hline
\end{tabular}

Fonte: Anuário Diplomatas 2010, elaboração do autor.

\section{Discussão e resultados}

Reitero que nessas relações estão teoricamente presentes tanto a agência dos diplomatas em suas circulações - que desenham seu desenvolvimento profissional e atuação político-burocrática no decorrer de suas carreiras -, quanto tais conexões mais amplas constroem os relacionamentos institucionais estabelecidos pelo próprio MRE - e que potencializam ou constrangem em alguma medida o comportamento dos atores que pertencem a sua burocracia, tendo em vista as necessidades e respostas sistêmicas do ministério. Essas interações constroem redes capazes de desenhar as vias de mão dupla do policy domain do Itamaraty, vulgo sua política externa institucional, compondo assim e de maneira mais geral, as redes de sua policy network.

Nesse sentido e de um lado, burocratas análogos ao tipo weberiano, tal como são classificados os diplomatas (Cheibub, 1985), podem atuar estratégica e politicamente em busca de legitimidade por não possuírem mandatos eletivos (Huber, 2007), além de estarem sujeitos a outras múltiplas pressões individuais e coletivas, profissionais e políticas (Dunleavy, 1991) - pari passu aos seus mandatos burocráticos e setoriais (Allison, 1969). De outro, estão as estruturas de conexões que configuram os relacionamentos estabelecidos pelo MRE, em que as burocracias per se tanto agem sob forças exógenas quanto possuem margem para iniciativa própria, isto é, a burocracia e o ambiente político estão em constante interação (Huber, 2007) - dado que um policy domain específico se relaciona e leva em consideração as ações de outras áreas substantivas e que são mutuamente acionadas para os eventos de policies intersecionados (Laumann \& Knoke, 1987). 
Evidentemente há um limite de alcance das conclusões que se podem traçar dessas relações mesmo porque não se tem a informação acerca do conteúdo transacional do agente e/ou dos mandatos ministeriais nos atos de interação institucional - seja a troca de recursos vários como informacionais, financeiros, intercâmbios de pessoal (idem), ou outros bens e serviços (Tichy, Tushman \& Fombrun, 1979). Por meio do enfoque aqui adotado se coloca mais peso analítico na estrutura da rede, ou seja, em sua configuração e entre as instituições mais centrais ou marginais, emergem os padrões advindos das instituições co-participadas que são resultados tanto das interações dos atores nesses intereventos (Laumann, Knoke \& Kim, 1987) quanto da forma que o ministério rege seu ambiente institucional e interage com os sistemas externos a ele (Lopes \& Baldi, 2009).

\section{IV.1 Hipóteses}

\footnotetext{
${ }^{8}$ Para consulta dos postos diplomáticos de $\mathrm{A}$ até $\mathrm{D}$, ver Portaria de $\mathrm{N}^{\circ} 534$ de 31 de Agosto de 2010, disponíveis no site da Associação Nacional dos Oficiais de Chancelaria do Serviço Exterior Brasileiro (Asof).
}

O MRE classifica seus postos no exterior em quatro classes, de "A" até "D". Dessa maneira, as embaixadas, consulados e unidades específicas no exterior pertencentes a classe "A", conforme Portaria de 2010 compatível com a data de atualização das informações do Anuário ${ }^{8}$, estão em: Barcelona, Berlim, Boston, Bruxelas, Buenos Aires, Chicago, Genebra, Lisboa, Londres, Los Angeles, Madri, Miami, Milão, Nova York, Paris, Roma, São Francisco, Viena e por último, porém não menos importante, Washington. Considera-se que os países que recebem tais unidades diplomáticas brasileiras, em geral centrais no sistema internacional, possuem um alto interesse político para a atuação do MRE e da participação de seus atores burocráticos, de um lado. De outro e consequentemente, por serem postos no exterior com mais recursos materiais - orçamento, staff, informações etc. - e não-materiais - como afinidades simbólicas e culturais (Amorim Neto, 2011) - que as unidades de outras classes, podemos considerar esses postos com maiores potencialidades e possibilidades de efetivação da política externa institucional do Itamaraty, dado a expectativa de relacionamentos diplomáticos mais ativos nessas instituições chave (H1).

Para os organismos internacionais, se reforça que a Organização das Nações Unidas (ONU) é a principal instituição política internacional (idem) e constitui em fundamental interesse, histórico e presente, para a política externa brasileira (ibidem; Lima \& Hirst, 2009). Entende-se desse modo que o Itamaraty possui alta preferência no relacionamento com esse organismo, além do envio sistemático e participativo de seus atores junto do sistema ONU. Dessa maneira, se constrói a hipótese de que o relacionamento prioritário nas instancias que compõe o guarda-chuva institucional da ONU é fundamental para a política externa institucional do MRE, considerando que essas conexões se constituem em oportunidades várias, desde angariar recursos políticos internacionais até consolidar tratados, estabelecer acordos formais e informais, negociações, parcerias e demais gestões multilaterais $(\mathrm{H} 2)$.

Em relação as instituições nacionais, cabe reiterar que o MRE consiste no braço constitucional, legal e de assessoramento político direto para assuntos diplomáticos e internacionais da Presidência da República. Soma-se o fato de que o papel de protagonismo institucional do ministério depende da omissão, autorização ou delegação da Presidência para suas atividades em política externa (Lima, 2000). Assume-se, portanto, que possuir relacionamento próximo com essa instituição que rege o sistema político nacional (Figueiredo \& Limongi, 1999) é essencial para a atuação política do ministério no nível doméstico, e é igual e politicamente incentivada a participação de seus atores nessa instituição ou junto dela. Dessa maneira e ao contrário dos críticos do modelo burocrático que enfatizavam que Allison (1969) concedia demasiado peso ao papel dos políticos e burocratas em detrimento do presidente, aqui se 
conjectura a hipótese da participação diplomática junto a Presidência da República. Assim e graças a combinação da APE com ARS, teoriza-se que essa relação será priorizada pela política externa institucional do ministério muito porque é da interação entre Chancelaria e Presidência que se potencializam oportunidades que vão desde a sobrevida ministerial até seu maior protagonismo dentro do poder executivo - demandando mais recursos, informações e suportes materiais e não-materiais nacionais associados ao enforcement de policies - e que também se conecta e se opera ao nível internacional, pelo reforço ou via de apoio diplomático do e ao presidente da república $(\mathrm{H} 3)$.

\section{IV.2 Força estrutural das conexões: As dez maiores centralidades institucionais (eigenvector centrality)}

Com vistas a verificar as hipóteses e construir as redes, a literatura que trata de political networks sugere que a posição de um ator, em determinada rede, se associa com o poder e influência que esse ator possui. Quanto maior a centralidade do ator, maior seu poder, tendo em vista seu acesso a instâncias decisórias ou mesmo seu controle sobre o fluxo de recursos, principalmente quando determinados atores são dependentes do ator-focal (Krackhardt, 2010; Brass \& Krackhardt, 2012). Há também aqueles que apontam que a estrutura e a posição de um ator na rede pode ser também um preditor de seu desempenho (Borgatti, Everett \& Johnson, 2013).

Em sintonia com as seções anteriores, observamos que o grau (degree ou grau de centralidade) se constitui em pontos de conexão para cada vizinho que um ator possui. No entanto, essa medida não leva em conta se os seus vizinhos são equivalentes, ou em outras palavras, nem todos os vizinhos podem ser populares na rede. Isto é e em muitas circunstâncias, a importância do ator é aumentada por possuir conexões com outros atores que também são muito importantes. Esse é o conceito que embasa o eigenvector centrality e que o faz uma variação do grau de centralidade. Ao invés de conferir um índice para cada vizinho - como a clássica mensuração de grau faz -, o eigenvector condiciona um score para cada ator proporcionalmente a soma dos scores dos seus vizinhos. Nesse aspecto, esse score aumenta ao passo que ou um ator tem muitos vizinhos, ou um ator tem vizinhos importantes, ou ambos (Newman, 2010). Soma-se que o eigenvector aceita dados valorados e positivos e assim podem ser interpretados como oportunidades, no sentido de que atores centrais tem contatos com os fluxos mais privilegiados ou possuem posições de destaque na coordenação na rede (Borgatti \& Halgin, 2011).

Destaco a seguir as dez instituições com os maiores eigenvectors, respectivamente coloridos e com foco nos centros dos Gráficos 3, 4 e 5 possuindo os

Gráfico 3 - Centralidade (Eigenvector) para segundos (esq.) e primeiros secretários (dir.)
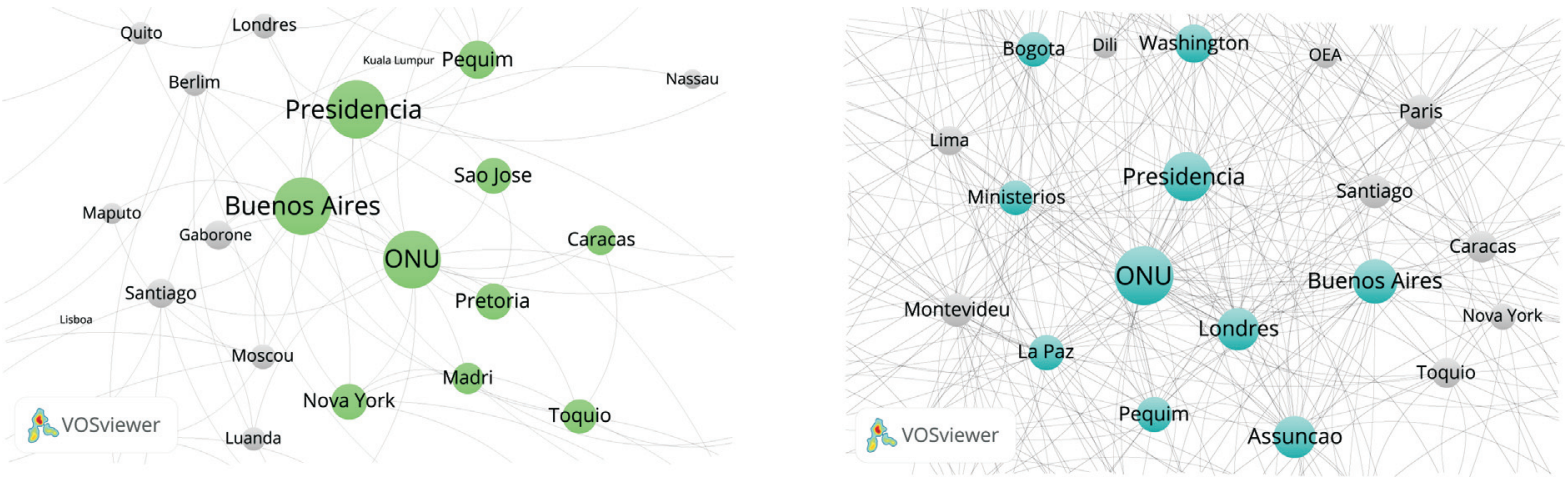

Fonte: Anuário Diplomatas 2010, elaboração do autor. 
Gráfico 4 - Centralidade (Eigenvector) para conselheiros (esq.) e segundos ministros (dir.)
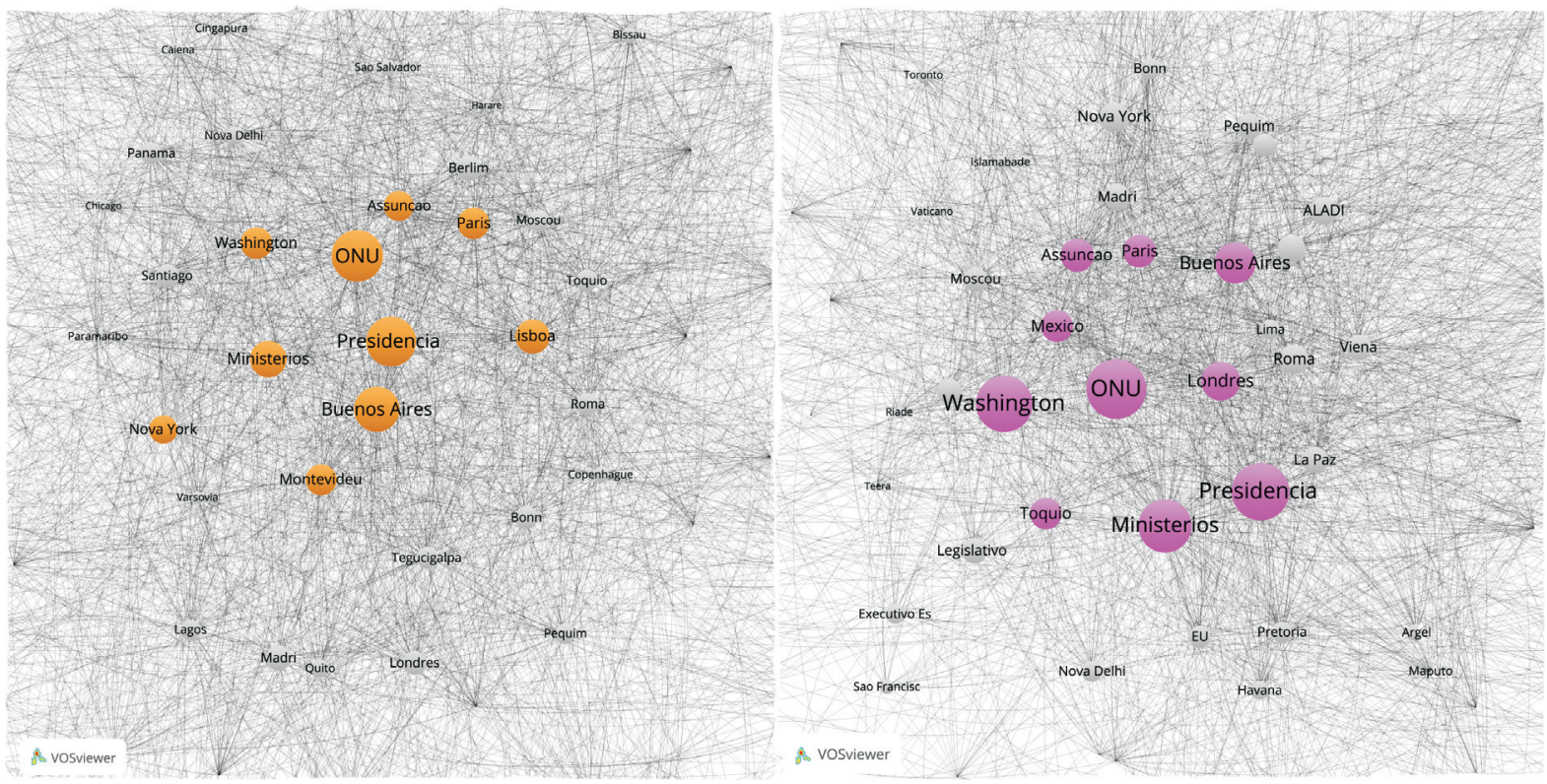

Fonte: Anuário Diplomatas 2010, elaboração do autor.

tamanhos dos nodos relacionados aos seus eigenvalues. Citados em ordem decrescente de seus scores, repare para o caso dos segundos secretários que os maiores valores dessa medida de centralidade se destacam para: Presidência da República, Buenos Aires, ONU, Pequim, São José, Pretoria, Nova York, Tóquio, Madri e Caracas (Gráfico 3). Para os primeiros secretários temos também entre as instituições com os mais altos eigenvalues: ONU, Presidência da República e Buenos Aires, em paralelo a Londres, Assunção, Washington, Pequim, La Paz, Ministérios e Bogotá (Gráfico 3).

Para os conselheiros e em comparação aos achados da base ministerial, vê-se que persistem com significativos valores de centralidade: ONU, Presidência da República e Buenos Aires, ao passo que a categoria de Ministérios sobe de posição, seguido por Lisboa, Paris, Washington, Montevidéu, Assunção e Nova York (Gráfico 4). Quando observamos a porta de entrada para a elite, temos no segundo mais alto patamar da carreira: ONU, Presidência da República, Washington, Ministérios e Buenos Aires, junto de Londres, Assunção, Paris, Tóquio e (cidade do) México (Gráfico 4).

Por fim e na mais alta elite, temos para os embaixadores e com as maiores centralidades: ONU, Presidência da República, Ministérios, Washington, Paris, Londres, Buenos Aires, Roma, OEA e Nova York (Gráfico 5). Desse modo e para o topo da carreira, nota-se em alguma medida, um padrão recorrente quando comparado as demais hierarquias, principalmente em relação a essas quatro primeiras instituições, adicionalmente a Buenos Aires.

Nas Tabelas 3 e 4 sintetizo os achados da seção. Reitera-se que para os três primeiros escalões analisados a ONU, a Presidência da República e Buenos Aires, figuram sistematicamente entre os três maiores eigenvalues. Igualmente a ONU e a Presidência aparecem entre as conexões mais centrais na alta hierarquia do MRE, seguidos por Washington e Ministérios que adquirem crescente relevância, conjuntamente a Paris, Buenos Aires e Londres que se mostraram recorrentes na elite diplomática. Para esse estrato funcional e em paralelo a categoria de Ministérios, cabe destacar que Assunção, Tóquio e (cidade do) México, para os segundos ministros, e a OEA, no caso dos embaixadores, estão 
Gráfico 5 - Centralidade (Eigenvector) para embaixadores

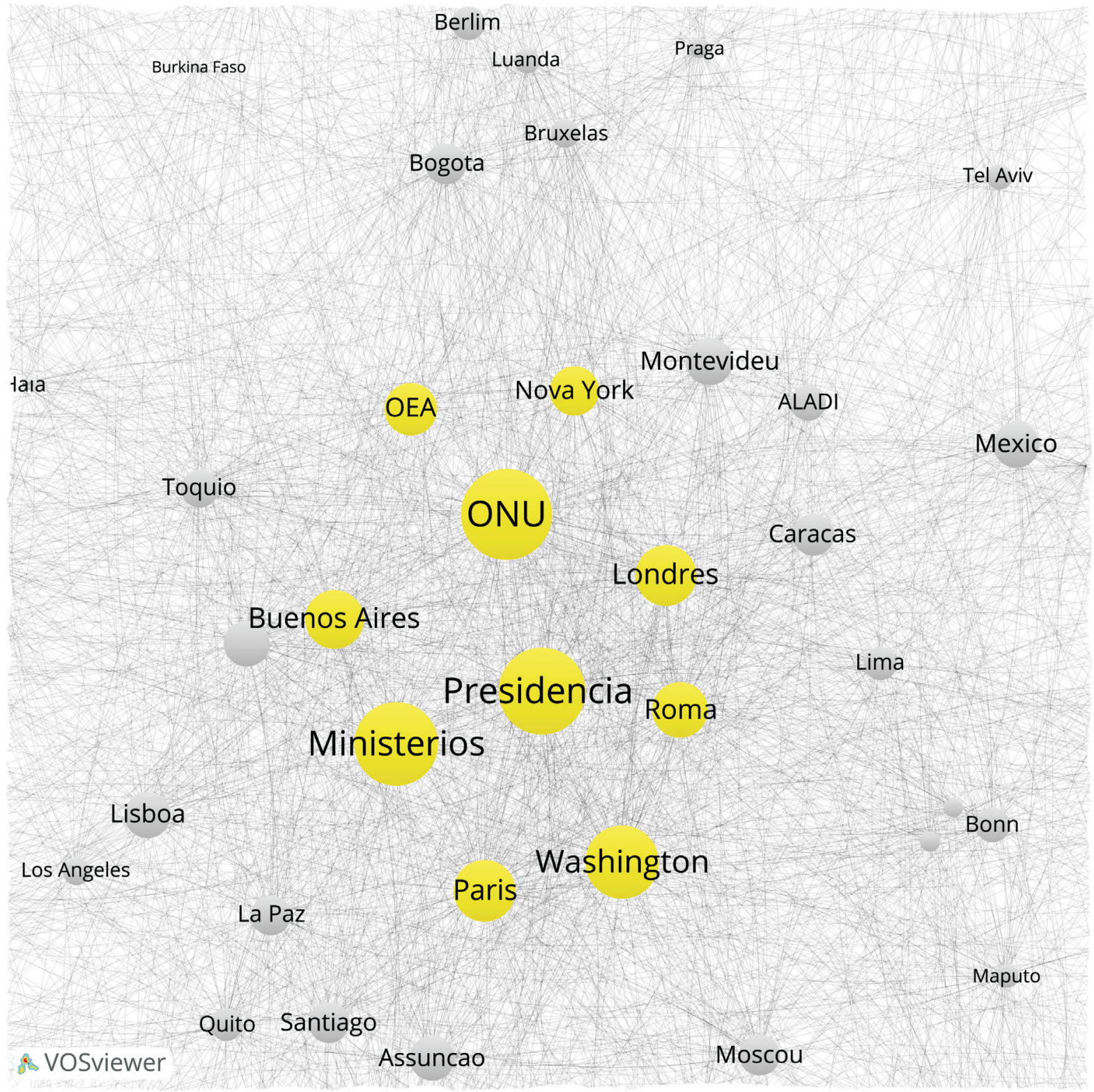

Fonte: Anuário Diplomatas 2010, elaboração do autor.

entre os dez principais resultados e vão além das hipóteses levantadas. Nesse aspecto, a base ministerial apresentou relacionamentos ainda mais diversificados, tendo nos secretariados: Pequim, São José, Pretoria, Caracas, La Paz e Bogotá, além dos supra citados Tóquio e Assunção. Para os conselheiros, a capital do Paraguai também figura junto da capital do Uruguai entre os maiores eigenvectors. Essas conexões heterogêneas e que fogem das hipóteses sugeridas, mostram o peso da China, África do Sul e Japão, além da evidencia sistemática de vizinhos da América do Sul, para os relacionamentos institucionais e diplomáticos dos estratos médios e baixos do ministério.

IV.3 Força estrutural agrupamentos: Os principais clusters hierárquicos (hierarchical clustering)

A seção anterior abordou quais instituições possuíam uma alta interconexão estrutural na rede - vulgo mais contatos mútuos pareados, relacionados uns aos 
Tabela 3 - Eigenvector centrality dos escalões baixo e intermediário

\begin{tabular}{|c|c|c|c|c|c|}
\hline \multicolumn{2}{|c|}{ Segundo Secretário } & \multicolumn{2}{|c|}{ Primeiro Secretário } & \multicolumn{2}{|c|}{ Conselheiro } \\
\hline Instituições & Eigenvalues & Instituições & Eigenvalues & Instituições & Eigenvalues \\
\hline Pres. da Rep. & 0.4736 & ONU & 0.4751 & ONU & 0.3507 \\
\hline Bs. Aires & 0.4647 & Pres. da Rep. & 0.3262 & Pres. da Rep. & 0.3346 \\
\hline ONU & 0.4593 & Bs. Aires & 0.2754 & Bs. Aires & 0.2924 \\
\hline Pequim & 0.2053 & Londres & 0.2486 & Ministerios & 0.2176 \\
\hline Sao Jose & 0.1809 & Assuncao & 0.2430 & Lisboa & 0.1959 \\
\hline Pretoria & 0.1809 & Washington & 0.2020 & Paris & 0.1750 \\
\hline Nova York & 0.1786 & Pequim & 0.1745 & Washington & 0.1749 \\
\hline Toquio & 0.1644 & $\mathrm{LaPaz}$ & 0.1703 & Montevideu & 0.1725 \\
\hline Madri & 0.1390 & Ministerios & 0.1674 & Assuncao & 0.1624 \\
\hline Caracas & 0.1257 & Bogota & 0.1669 & Nova York & 0.1520 \\
\hline Média & 0.0540 & Média & 0.0517 & Média & 0.0492 \\
\hline Desvio-p. & 0.0941 & Desvio-p. & 0.0713 & Desvio-p. & 0.0533 \\
\hline
\end{tabular}

Fonte: Anuário Diplomatas 2010, elaboração do autor. Utilizado Pajek > Vector > Hubs-authorities (info).

Tabela 4 - Eigenvector centrality da elite do MRE

\begin{tabular}{ccccc}
\hline \multicolumn{2}{c}{ Segundos Ministros } & & \multicolumn{2}{c}{ Embaixadores } \\
\cline { 1 - 2 } \cline { 5 - 5 } Instituições & Eigenvalues & & Instituições & Eigenvalues \\
\hline ONU & 0.3947 & & ONU & 0.4528 \\
Pres. da Rep. & 0.3747 & & Pres. da Rep. & 0.4155 \\
Washington & 0.3595 & & Ministerios & 0.3867 \\
Ministerios & 0.3266 & & Washington & 0.2949 \\
Bs. Aires & 0.2178 & & Paris & 0.2066 \\
Londres & 0.1973 & & Londres & 0.2044 \\
Assuncao & 0.1540 & & Bs. Aires & 0.1885 \\
Paris & 0.1511 & & Roma & 0.1680 \\
Toquio & 0.1416 & & OEA & 0.1480 \\
Mexico & 0.1414 & & Nova York & 0.1310 \\
Média & 0.0401 & & Média & 0.0309 \\
Desvio-padrão & 0.0602 & & Desvio-padrão & 0.0615 \\
\hline
\end{tabular}

Fonte: Anuário Diplomatas 2010, elaboração do autor. Utilizado Pajek > Vector > Hubs-authorities (info).

outros, e entre os atores mais importantes da rede. Vimos que a posição que o nó ocupa corresponde a um particular padrão de suas conexões, sendo que a literatura de ARS sugere que as posições de centralidade têm um forte efeito sobre oportunidades, fluxos, coordenações e acessos.

Contudo, existem outros indicadores que enfatizam aspectos para além da posição e centralidade, e a ênfase nessa parcela do artigo recai sobre a mensuração da equivalência estrutural de agrupamentos que buscam evidenciar como arranjos estruturais de grupos otimizam essas conexões, com base nos atores e seus padrões similares de conexões (Burt, 1992). Nesse quesito, a literatura defende que os atores que mais prosperam são os que possuem redes imediata- 
mente densas e também estão ligados às redes mais distantes, caracterizadas por múltiplos contatos não redundantes - sendo os contatos redundantes aqueles dirigidos aos mesmos atores e que, portanto, levam às mesmas informações e os mesmos benefícios (idem; Lopes \& Baldi, 2009).

As medidas de coesão e equivalência estrutural buscam exatamente capturar os padrões entre contatos não redundantes, sendo que a primeira métrica se relaciona com a conexão direta, já a equivalência estrutural se refere também a conexão indireta (idem). Para essa última medida, a identificação de atores que possuem padrões similares de conexões em agrupamentos (clusters) sugerem que os atores em um mesmo grupo devem ser homogêneos entre si e heterogêneos com os demais atores, com base na estrutura da rede. A equivalência estrutural então se baseia na similaridade entre os atores, e em geral, são considerados equivalentes estruturalmente quando possuem linhas e colunas idênticas - exceto pelas células da diagonal, em uma matriz adjacente (Nooy, Mrvar \& Batagelj, 2005).

Para analisar a equivalência estrutural utilizo a medida de agrupamento hierárquico ou hierarchical clustering (o Pajek usa o algoritmo Ward como default) para distancias euclidianas (d5 no Pajek) que leva em consideração os valores das linhas - quanto menor a dissimilaridade maior a homogeneidade do cluster. Desse modo, a distância euclidiana requer equivalência estrutural tanto de input e output entre os nós, quanto os valores dos laços também devem possuir intensidade comparável (idem).

Feitos alguns coortes nos clusters para o incremento da similaridade, podese notar a seguir que para ambos os secretariados os agrupamentos centrais apresentam igualmente a ONU (Gráfico 6). Para os segundos secretários a Presidência da República e Buenos Aires estão também nesse grupo, já para os primeiros secretários orbitam a ONU, no cluster secundário, outros organismos internacionais como ALADI e MERCOSUL.

Para a camada média e a de ingresso na elite diplomática, a dupla institucional ONU e Presidência da República constam nos agrupamentos hierárquicos primordiais de ambos esses estratos funcionais (Gráfico 7). No caso dos conselheiros figura também Buenos Aires, ao passo que para os segundos ministros Washington e Ministérios estão presentes no cluster principal.

Para os embaixadores, se observa novamente que a ONU e a Presidência mostram equivalência estrutural ao lado dos demais Ministérios e Washington, que também se incluem nesse mais importante agrupamento (Gráfico 8). Em

Gráfico 6 - Densidades de agrupamento hierárquico para segundos (esq.) e primeiros secretários (dir.)

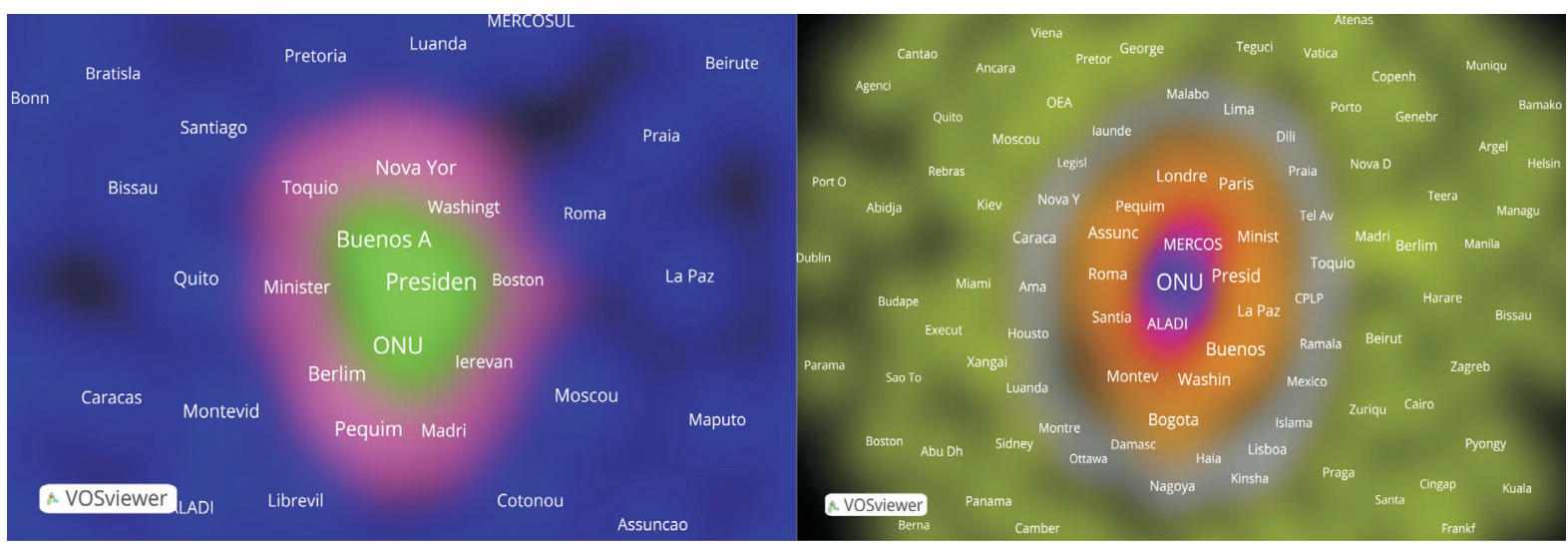

Fonte: Anuário Diplomatas 2010, elaboração do autor. 
Gráfico 7 - Densidades de agrupamento hierárquico para conselheiros (esq.) e segundos ministros (dir.)

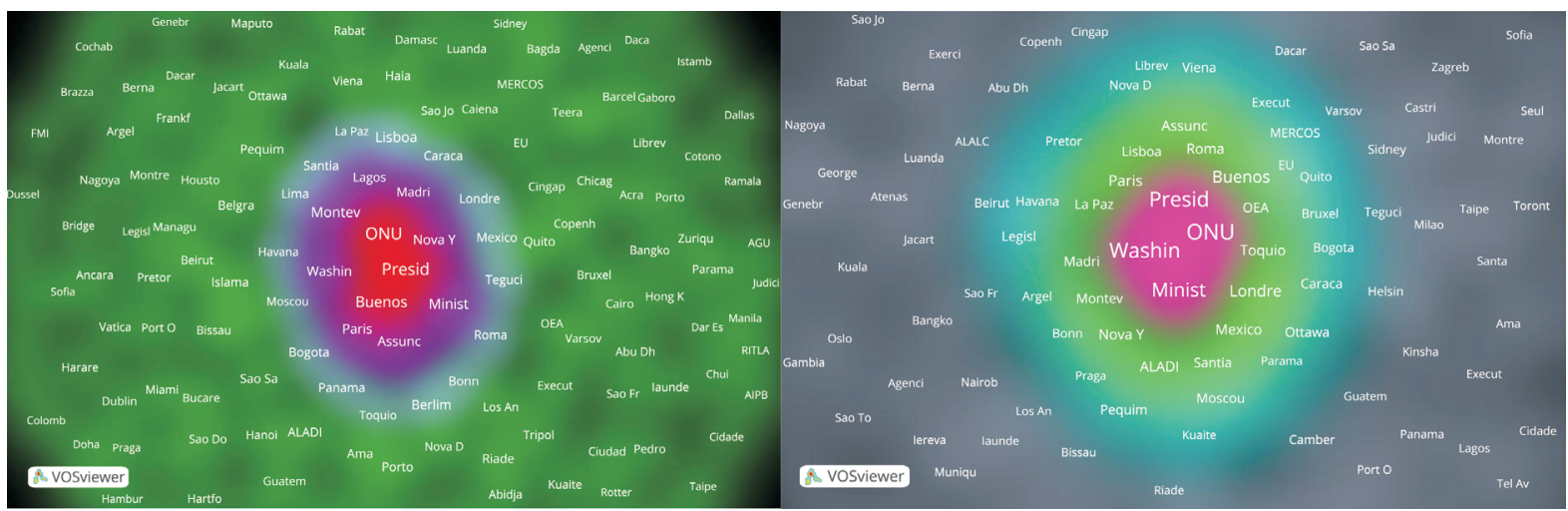

Fonte: Anuário Diplomatas 2010, elaboração do autor.

suma para os resultados da seção, se nota que a ONU pertence aos clusters principais de todas as hierarquias avaliadas, Buenos Aires aparece nos agrupamentos dos segundos secretários e conselheiros, e Washington esteve presente nas classes da elite ministerial. Ademais, a Presidência da República foi sistemática ao longo dos estratos funcionais analisados - com exceção dos primeiros secretários - e a categoria de Ministérios, para além das hipóteses levantadas, esteve presente também nos clusters centrais da elite do MRE.

\section{Conclusões}

A presente pesquisa conectou as participações dos diplomatas por instituições e desenhou os relacionamentos institucionais do Ministério das Relações

Gráfico 8 - Densidades de agrupamento hierárquico para embaixadores

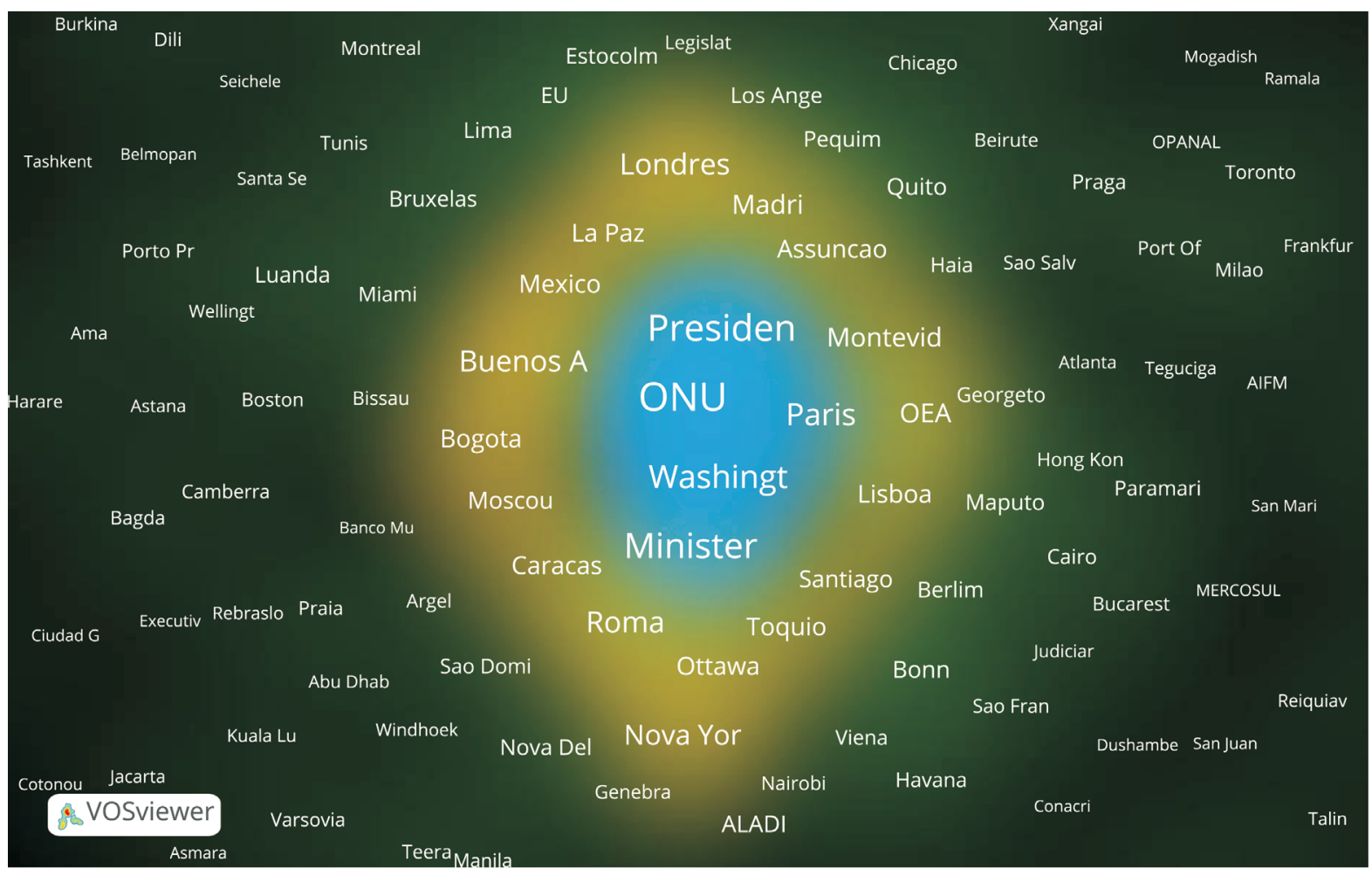

Fonte: Anuário Diplomatas 2010, elaboração do autor. 
Exteriores em redes - respectivamente a cada um dos distintos níveis funcionais da diplomacia nacional. A utilização de um banco de dados original, combinando a literatura de análise de política externa e de redes, junto as suas técnicas de projeção, permitiu analisar a dualidade indivíduo-instituição, derivando os padrões das circulações diplomáticas que compõe, em última instancia, as cadeias de conexões e estruturas de relacionamentos institucionais do MRE.

Essas relações são canais que estruturam a comunicação, informação e recursos institucionais, de um lado sob o trânsito, carreira e coordenação burocrática dos diplomatas, e de outro e necessariamente, vis-à-vis as demandas, recursos e respostas políticas sistêmicas do próprio ministério. Isto é, a partir das dinâmicas entre indivíduos e instituições - com capacidades e autonomias respectivas, em que um molda relativamente o outro no compasso das interações -, temos como resultado a estrutura das policy networks do Itamaraty, aqui intituladas de redes da política externa institucional brasileira. Esse meio campo relacional apresenta oportunidades de fluxos, controles, acessos e constrangimentos materiais e não-materiais, advindos do conflito e cooperação político-burocráticos, e permitem observar sob a estrutura das redes, quais instituições são priorizadas ou ocupam posições mais privilegiadas do que outras, mediante os padrões de co-participação institucional dos atores do ministério.

Para tanto propus utilizar duas métricas. A primeira medida de centralidade (eigenvector centrality), mostrou que as interconexões estruturais em muito se equiparam aos padrões encontrados para a segunda mensuração de equivalência estrutural de agrupamentos (hierarchical clustering). Em síntese e começando pelos achados coadjuvantes, destaco os dois principais postos diplomáticos da classe "A" no relacionamento institucional do Itamaraty (H1). Um é Buenos Aires que apresentou relevância sistemática para a base e para o estrato intermediário da burocracia diplomática, e o outro é Washington, que possui alta importância na elite ministerial. Nesse sentido, do baixo ao alto escalão e dentre as hipóteses sugeridas, se nota que são enfatizados respectivamente os relacionamentos regional e continental, mediante o paradigma sistemático da política externa institucional brasileira que vai no sentido da aproximação preferencial com os vizinhos locais e globais tradicionalmente estratégicos, respectivamente a Argentina e os Estados Unidos.

Para o relacionamento com os demais Ministérios, visualizado de modo recorrente nos segmentos da elite, e se constituindo em um achado que vai além das hipóteses levantadas, fica em aberto investigar de que modo esse intercambio horizontal se traduz. Assim e de que maneira essas pontes e ramificações se convertem em cooperação ou conflito institucional, como as inter-setorialidades dessas relações produzem políticas públicas, ou em que medida a conexão intensa com as burocracias do executivo federal flexibiliza ou põe em cheque o caráter fechado, autônomo, ou mais ou menos insulado do MRE, são elementos que vão além da proposta do artigo e que permanecem em aberto para futuras investigações. O que se pode afirmar a respeito desses pontos, no entanto, é que de fato há um empenho reiterado no sentido de exportar diplomatas para outros ministérios do poder executivo federal, aspecto que potencializa e possivelmente gera dividendos e recursos políticos domésticos, materiais e não-materiais, dos mais variados ao MRE.

Para os achados protagonistas das redes, a ONU e a Presidência da República se destacaram como as instituições mais centrais e estruturalmente dominantes, desde a base secretarial até a elite do Itamaraty, confirmando as hipóteses esperadas para as preferências de relacionamentos do MRE com essas duas arenas institucionais ( $\mathrm{H} 2$ e H3). Assim, se evidencia que essas duas altas prioridades se direcionam aos centros dos sistemas políticos, tanto de nível 
interno quanto externo. Em um provável jogo político de dois níveis, as redes da política externa institucional do MRE mostram que as conexões e estruturas hierárquicas desses relacionamentos institucionais estão em consonância com a natureza do seu domínio político. Nesse sentido e por atuar nacional e internacional simultaneamente, o Ministério das Relações Exteriores necessita fomentar oportunidades e fluxos relacionais para manter, angariar e coordenar recursos materiais e não-materiais, em ambos níveis, que o permita aumentar, otimizar e efetivar sua política externa institucional a nível doméstico, internacional e multilateral.

Rodolfo de Camargo Lima (rodolfodecamargolima@gmail.com) é Doutor em Ciência Política pela USP e professor do Departamento de Sociologia, Ciência Política e Administração Pública da UC Temuco.

\section{Referências}

Aberbach, J., Putnam, R. \& Rockman, B. (1981) Bureaucrats \& Politicians in Western Democracies.Massachusetts: Harvard University Press.

Abrucio, F. L., Loureiro, M. R. \& Pacheco, R. S. (2010) Burocracia e Política no Brasil: Desafios para a Ordem Democrática no Século XXI. Rio de Janeiro: FGV.

Allison, G. T. (1969) Conceptual Models and the Cuban Missile Crisis. American Political Science Review, 63(3), pp. 689-718. DOI: $10.2307 / 1954423$

Amorim Neto, O. (2011) De Dutra a Lula: A Condução e os Determinantes da Politica Externa Brasileira. Rio de Janeiro: Elsevier.

Art, R. J. (1973) Bureaucratic Politics \& American Foreign Policy: A Critique. Policy Sciences, 4(4), pp. 467-490. DOI: 10.1007/BF01728472

Baird, M. (2020) Saúde em jogo: atores e disputas de poder na Agência Nacional de Saúde Suplementar. Rio de Janeiro: Editora Fiocruz.

Batagelj, V. \& Mrvar, A. (1996) Pajek - Program for Large Network Analysis (version 5.05). University of Ljubljana. Disponível em: <http://vlado.fmf.uni-lj.si/pub/networks/pajek/>. Acesso em: 14 de abr. 2021.

Bersch, K. Praça S. \& Taylor, M. M. (2017) State Capacity, Bureaucratic Politicization, and Corruption in the Brazilian State. Governance, 30(1), pp. 105-24. DOI: 10.1111/gove.12196

Borgatti, S. P., Everett, M. G. \& Jeffrey C. J. (2013) Analyzing Social Networks. London: SAGE Publications Inc.

Borgatti, S. P. \& Halgin, D. S. (2011) Analyzing Affiliation Networks. In J. Scott \& P. J. Carrington (orgs) The SAGE Handbook of Social Network Analysis. London, California, New Delhi, Singapore: SAGE Publications Inc, pp. 417-33.

Borgatti, S., Freeman, L. C. \& Everett, M. G. (2002) Ucinet 6 for Windows: Software for Social Network Analysis (version 6.662). Ucinet. Massaschusetts: Analytic Technologies. Disponível em: $<$ https://sites.google.com/site/ucinetsoftware/home>. Acesso em: 14 de abr. 2021.

Brass, D. \& Krackhardt, D. (2012) Power, Politics, \& Social Networks in Organizations. In G. R. Ferris \& D. C. Treadway (orgs) Politics in Organizations: Theory \& Research Considerations. New York: Routledge, Taylor \& Francis Group, pp. 355-75.

Breiger, R. L. \& Mohr, J. W. (2004) La dualidad y la agregación de categorías sociales. Rede. Revista hispana para el análisis de redes sociales, $5(4)$.

Burt, R. S. (1992) Structural Holes: The Social Structure of Competition. London: Harvard University Press.

Cason, J. W. \& Power, T. J. (2009) Presidentialization, Pluralization, and the Rollback of Itamaraty: Explaining Change in Brazilian Foreign Policy Making in the Cardoso-Lula Era. International Political Science Review, 30(2), pp. 117-40. DOI: $10.1177 / 0192512109102432$

Cepik, M. \& Möller, G. (2017). National Intelligence Systems as Networks: Power Distribution \& Organizational Risk in Brazil, Russia, India, China, \& South Africa. Brazilian Political Science Review, 11(1), pp. 1-26. DOI: 10.1590/1981-3821201700010001

Cheibub, Z. B. (1985) Diplomacia e Construção Institucional: O Itamaraty Em Uma Perspectiva Histórica. Dados - Revista de Ciências Sociais, 28(1), pp. 113-31.

Cheibub, Z. B . (1989) A Carreira Diplomática no Brasil: O Processo de Burocratização do Itamarati. Revista de Administração Pública, 23(2), pp. 97-128.

Diniz, S. \& Ribeiro, C. O. (2008) The Role of the Brazilian Congress in Foreign Policy. Brazilian Political Science Review 2(2), pp. 10-38.

Dunleavy, P. (1991) Democracy, Bureaucracy and Public Choice. London: Havester Wheatsheaf.

Eck, N. J. V. \& Waltman, L. (2009) VOSviewer: Visualizing Scientific Landscapes (version 1.6.8). Leiden University: Centre for Science \& Technology Studies. Disponível em: <http://www.vosviewer.com/>. Acesso em: 14 de abr. 2021.

Figueiredo, A. M. C. \& Limongi, F. P. (1999) Executivo e legislativo na nova ordem constitucional. Rio de Janeiro: FGV.

Foss, P. (1995) Economic Approaches to Organizations \& Institutions: An Introduction. Aldershot: England; Brookfield: United States; Dartmouth Pub Co. 
França, C. L. \& Badin, M. R. S. (2010) A Inserção Internacional do Poder Executivo Federal Brasileiro. Fundação Friedrich Ebert, Análises e Propostas, s/v(40).

Geddes, B. (1996) Politician's Dilemma: Building State Capacity in Latin America. Berkley, Los Angeles, London: University of California Press.

Hafner-Burton, E. M., Kahler, M. \& Montgomery, A. H. (2009). Network Analysis for International Relations. International Organization, 63(3), pp. 559-92. DOI: 10.1017/S0020818309090195

Huber, G. A. (2007) The Craft of Bureaucratic Neutrality. New York: Cambridge University Press.

Huckfeldt, R. (2009) Interdependence, Density Dependence, \& Networks in Politics." American Politics Research, 37(5), pp. 921-50. DOI: 10.1177/1532673X09337462

Hudson, V. M. (2013) Foreign Policy Analysis: Classic \& Contemporary Theory. London: Rowman \& Littlefield.

Jones, C. M. (2010) Bureaucratic Politics and Organizational Process Models. In R. Denemark (orgs) The International Studies Compendium. London: Blackwell Publishing.

Kenis, P. \& Schneider, V. (1991) Policy Networks \& Policy Analysis: Scrutinizing a New Analytical Toolbox. In B. Marin \& R. Mayntz (orgs) Policy Networks: Empirical Evidence \& Theoretical Considerations, Boulder: Westview Press, pp. 25-59.

Knoke, D. (2001) Changing Organizations: Business Networks in the New Political Economy. Boulder: Westview Press.

Knoke, D., Pappi, F. U., Jeffrey, B. \& Tsujinaka, Y. (1996). Comparing Policy Networks: Labor Politics in the U.S., Germany, \& Japan. New York: Cambridge University Press.

Krackhardt, D. (2010) Social Networks. In J. M. Levine \& M. A. Hogg. Encyclopedia of Group Processes and Intergroup Relations. Los Angeles: SAGE Publications Inc., pp. 817-21.

Krasner, S. D. (1972) Are Bureaucracies Important? (Or Allison Wonderland). Foreign Policy, s/v(7), pp. 159-79. DOI: $10.2307 / 1147761$

Laumann, E. O. \& Knoke, D. (1987) The Organizational State: Social Choice in National Policy Domains. Madison: The University of Wiscosin Press.

Laumann, E. O., Knoke, D. \& Kim, Y. (1987) Organizational Participation in Decision-Making Events. In E. O. Laumann \& D. Knoke. The Organizational State: Social Choice in National Policy Domains. Madison: The University of Wiscosin Press, pp. 271-87.

Lima, M. R. S. (2000) "Instituições Democráticas e Política Exterior.” Contexto Internacional, 22(2), pp, 265-303.

Lima, M. R. S. \& Hirst, M. (2009) Brasil como País Intermediário e Poder Regional. In A. Hurrell et al. Os Brics e a Ordem Global. Rio de Janeiro: FGV, pp. 43-74.

Lima, R. de C. (2019) Burocratas, carreira e política: uma análise das trajetórias da elite do Ministério das Relações Exteriores. Revista do Serviço Público, 70(3), pp. 486-510. DOI: 10.21874/rsp.v70i3.1481

Lima, R. de C. \& Oliveira, A. J. S. N (2018) Manutenção e mudanças no Ministério das Relações Exteriores: perfis do corpo diplomático e padrões na carreira. Revista de Administração Pública, 52(5), pp. $797-821$. DOI:10.1590/0034-7612175199

Lopes, F. D. \& Baldi, M. (2009) Redes como perspectiva de análise e como estrutura de governança: uma análise das diferentes contribuições. Revista de Administração Pública 43(5), pp, 1007-35. DOI: 10.1590/S0034-76122009000500003

Lopez, F. G. (2015) Evolução e Perfil Dos Nomeados para Cargos DAS na Administração Pública Federal (1999-2014). [online] Nota Técnica, Brasília: IPEA, pp. 1-19. Disponível em: <http://fernandomanica.com.br/site/wp-content/uploads/2015/10/Nota-Tecnica-IPEA.pdf $>$.

Lotta, G.(2018) Burocracia, redes sociais e interação: uma análise da implementação de políticas públicas. Revista de Sociologia e Politica, 26(66), pp. 145-73. DOI: 10.1590/1678-987318266607

Loureiro, M. R. \& Abrucio, F. L. (1999) Política e Burocracia no Presidencialismo Brasileiro: O Papel do Ministério da Fazenda no Primeiro Governo Fernando Henrique Cardoso. Revista Brasileira de Ciências Sociais, 14(41), pp. 69-89. DOI: 10.1590/S0102-69091999000300005

Marques, E. C. L. (2006). Redes Sociais e Poder No Estado Brasileiro: Aprendizados a Partir das Políticas Urbanas. Revista Brasileira de Ciências Sociais, 21(60), pp.15-41. DOI: 10.1590/S0102-69092006000100002

Marques, E. C. L. (2017) A Rede dos Gestores Locais em São Paulo. Dados - Revista de Ciências Sociais, 60(2), pp. 437-72. DOI: $10.1590 / 001152582017125$

Marsh, K. (2013) Obama's Surge: A Bureaucratic Politics Analysis of the Decision to Order a Troop Surge in the Afghanistan War. Foreign Policy Analysis, 10(3), pp. 265-88. DOI: 10.1111/fpa.12000

McClurg, S. D. \& Lazer, D. (2014) Political Networks. Social Networks, 36(s/n), pp. 1-4. DOI: 10.1016/j.socnet.2013.09.001.

Newman, M. (2010) Networks: An Introduction. New York: OUP Oxford.

Nooy, W., Mrvar, A. \& Batagelj, V. (2005) Exploratory Network Analysis with Pajek. New York: Cambridge University Press.

Olivieri, C. (2007) Política, Burocracia e Redes Sociais: As nomeações para o alto escalão do Banco Central do Brasil. Revista de Sociologia e Política, s/v(29), pp. 147-68. DOI: 10.1590/S0104-44782007000200011

Ostrom, V. \& Ostrom, E. (1971) Public Choice: A Different Approach to the Study of Public Administration. Public Administration Review, 31(2), pp. 203-16. DOI: 10.2307/974676

Perissinotto, R. M., Cavalieri, M. A. R., Dantas, E. G. \& Dias, R. P. (2017) Redes Sociais e Recrutamento: O Caso dos Diretores e Presidentes do Banco Central Do Brasil (1994-2016). Tempo Social, 29(3), pp. 61-82. DOI: 10.11606/0103-2070.ts.2017.125881 
Perlmutter, A. (2011) The Presidential Political Center and Foreign Policy: A Critique of the Revisionist and Bureaucratic-Political Orientations. World Politics, 27(1), pp. 87-106. DOI: 10.2307/2009927

Pinheiro, L. \& Milani, C. R. S. (2012) Política Externa Brasileira: A Política das Práticas e as Práticas da Política. Rio de Janeiro: FGV.

Rosati, J. A. (1981). Developing a Systematic Decision-Making Framework: Bureaucratic Politics in Perspective. World Politics, 33(2), pp. 234-52. DOI: 10.2307/2010371

Stein, A. A. (2006). Constraints \& Determinants: Structure, Purpose, \& Process in the Analysis of Foreign Policy. In H. Starr (orgs) Approaches, Levels, \& Methods of Analysis in International Politics: Crossing Boundaries. New York: Palgrave Macmillan, pp. 189-212.

Tichy, N. M., Tushman, M. L. \& Fombrun, C. (1979) Social Network Analysis for Organizations. The Academy of Management Review, 4(4), pp. 507-19. DOI: 10.2307/257851

Ward, M. D., Stovel, K. \& Sacks, A. (2011) Network Analysis \& Political Science. Annual Review of Political Science, 14(1), pp. 245-64. DOI: 10.1146/annurev.polisci.12.040907.115949

Wu, C. \& Knoke, D. (2013) Policy Network Models. In E. Araral. Routledge Handbook of Public Policy. London, New York: Routledge Handbooks, pp. 153-64

Brazilian foreign policy networks: Diplomatic circulation and institutional relationships of Ministry of Foreign Affairs

KEYWORDS: Ministry of Foreign Affairs; social network analysis; bureaucrats; public policies; foreign policy

ABSTRACT Introduction: The patterns of participation and institutional circulation of Brazilian diplomats allow us to understand the bureaucratic politics' relationships of the Ministry of Foreign Affairs (MFA or Itamaraty) and, therefore, the priorities of Brazil's foreign policy networks. Materials and Methods: The database information comes from the diplomats' 2010 Yearbook, and the research analyzes their co-participation in various institutions according to their hierarchical positions within the Ministry. The hypothesis considers that the MFA's primary relationships relate to class A diplomatic posts, the Presidential Office, and the United Nations. The paper uses the social network analysis methodology and its measures of eigenvector centrality and hierarchical clustering. Results: The structure of the networks showed a high concentration of institutional connections under a center-periphery shape. On the one hand and among class A diplomatic posts, Buenos Aires and Washington stood out. On the other hand, the United Nations Organization and the Presidential Office were the institutions that performed the highest centrality values and hierarchical clustering patterns among all the diplomats' tiers. Discussion: The diplomatic posts in Argentina's capital, for the low and medium diplomatic strata, and in the capital of the United States, for the ministerial elite, reinforce that the Brazilian institutional foreign policy relational interdependencies remain closely tied to both primary and traditional strategic partners. The United Nations and the Presidential Office demonstrate that Itamaraty's political domain reaches the external and domestic systems' political cores. Due to this bureaucratic politics' nature, the Ministry of Foreign Affairs has to foster opportunities and fluxes with these institutions to maintain, establish and coordinate resources, allowing the implementation of its public policy networks at the domestic, international, and multilateral levels.

This is an Open Access article distributed under the terms of the Creative Commons Attribution Non-Commercial License which permits unrestricted non-commercial use, distribution, and reproduction in any medium provided the original work is properly cited.

A produção desse manuscrito foi viabilizada através do patrocínio fornecido pelo Centro Universitário Internacional Uninter à Revista de Sociologia e Política. 